\title{
Epidemic and pandemic viral infections: impact on tuberculosis and the lung
}

\author{
A consensus by the World Association for Infectious Diseases and \\ Immunological Disorders (WAidid), Global Tuberculosis Network (GTN), and \\ members of the European Society of Clinical Microbiology and Infectious \\ Diseases Study Group for Mycobacterial Infections (ESGMYC)
}

Catherine Wei Min Ong (D) ${ }^{1,2,42,43}$, Giovanni Battista Migliori (1D ${ }^{3,42}$, Mario Raviglione ${ }^{4,5}$, Gavin MacGregor-Skinner ${ }^{6}$, Giovanni Sotgiu (iD) ${ }^{7}$, Jan-Willem Alffenaar ${ }^{8,9,10,43}$, Simon Tiberi (1D) 11,12,43 Cornelia Adlhoch (10 ${ }^{13,44}$, Tonino Alonzi ${ }^{14}$, Sophia Archuleta', Sergio Brusin ${ }^{13,44}$, Emmanuelle Cambau '15,43 Maria Rosaria Capobianchi ${ }^{16}$, Concetta Castilletti ${ }^{16}$, Rosella Centis (iD) ${ }^{3}$, Daniela M. Cirillo (iD) ${ }^{17,43}$

Lia D’Ambrosio (D) ${ }^{18}$, Giovanni Delogu ${ }^{19,20,43}$, Susanna M.R. Esposito ${ }^{21}$, Jose Figueroa ${ }^{22}$, Jon S. Friedland (iD) ${ }^{23,43}$, Benjamin Choon Heng Ho (D) ${ }^{24}$, Giuseppe Ippolito ${ }^{25}$. Mateja Jankovic (DiD ${ }^{26,43}$. Hannah Yejin Kim ${ }^{8,9,10}$, Senia Rosales Klintz $z^{13,44}$, Csaba Ködmön ${ }^{13,44}$, Eleonora Lalle ${ }^{16}$, Yee Sin Leo ${ }^{27}$, Chi-Chiu Leung ${ }^{28}$, Anne-Grete Märtson (1D) ${ }^{29}$, Mario Giovanni Melazzini ${ }^{30}$, Saeid Najafi Fard ${ }^{14}$, Pasi Penttinen (D) ${ }^{13,44^{\prime}}$ Linda Petrone ${ }^{14}$, Elisa Petruccioli ${ }^{14}$, Emanuele Pontali ${ }^{31}$, Laura Saderi iD $^{7}$, Miguel Santin (D) ${ }^{32,33,43}$, Antonio Spanevello ${ }^{34,35}$, Reinout van Crevel $^{36,37,43}$, Marieke J. van der Werf (D) ${ }^{13,44}$, Dina Visca $\mathbb{B}^{34,35}$ Miguel Viveiros ${ }^{38,43}$, Jean-Pierre Zellweger ${ }^{39}$, Alimuddin Zumla ${ }^{40}$ and Delia Goletti ${ }^{14,41,43}$

@ERSpublications

This consensus statement describes the effects of the viral infections resulting in epidemics and pandemics affecting the lung (MERS, SARS, HIV, influenza A (H1N1)pdm/09 and COVID-19) and their interactions with $\mathrm{TB}$, the top infectious disease killer https://bit.ly/2UUjhGu

Cite this article as: Ong CWM, Migliori GB, Raviglione M, et al. Epidemic and pandemic viral infections: impact on tuberculosis and the lung. Eur Respir J 2020; 56: 2001727 [https://doi.org/10.1183/ 13993003.01727-2020].

ABSTRACT Major epidemics, including some that qualify as pandemics, such as severe acute respiratory syndrome (SARS), Middle East respiratory syndrome (MERS), HIV, influenza A (H1N1)pdm/09 and most recently COVID-19, affect the lung. Tuberculosis (TB) remains the top infectious disease killer, but apart from syndemic TB/HIV little is known regarding the interaction of viral epidemics and pandemics with TB. The aim of this consensus-based document is to describe the effects of viral infections resulting in epidemics and pandemics that affect the lung (MERS, SARS, HIV, influenza A (H1N1)pdm/09 and COVID-19) and their interactions with TB. A search of the scientific literature was performed. A writing committee of international experts including the European Centre for Disease Prevention and Control Public Health Emergency (ECDC PHE) team, the World Association for Infectious Diseases and Immunological Disorders (WAidid), the Global Tuberculosis Network (GTN), and members of the European Society of Clinical Microbiology and Infectious Diseases (ESCMID) Study Group for Mycobacterial Infections (ESGMYC) was established. Consensus was achieved after multiple rounds of revisions between the writing committee and a larger expert group. A Delphi process involving the core group of authors (excluding the ECDC PHE team) identified the areas requiring review/consensus, followed by a second round to refine the definitive consensus elements. The epidemiology and immunology of these viral infections and their interactions with TB are discussed with implications for diagnosis, treatment and prevention of airborne infections (infection control, viral containment and workplace safety). This consensus document represents a rapid and comprehensive summary on what is known on the topic. 


\section{Introduction}

The 21 st century has been marked by major epidemics, including some that qualify as pandemics, caused by old diseases such as cholera, plague and yellow fever, as well as emerging diseases such as severe acute respiratory syndrome (SARS), Ebola, Zika, Middle East respiratory syndrome (MERS), HIV (although technically endemic), influenza A (H1N1)pdm/09 and most recently COVID-19. Several of these viruses affect the lung. Tuberculosis (TB) remains the top infectious disease killer caused by a single organism and was responsible for 1.5 million deaths in 2018 [1]. Apart from syndemic TB/HIV, little is known regarding the interaction of other viral epidemics with TB. This consensus-based document describes the effects of the main viral epidemics which predominately affect the lungs or cause systemic immunosuppression (MERS, SARS, HIV, influenza $\mathrm{A}(\mathrm{H} 1 \mathrm{~N} 1) \mathrm{pdm} / 09$ and COVID-19) and their interactions with TB at a diagnostic, treatment and public health level. The document is the fruit of a collaborative project involving the European Centre for Disease Prevention and Control Public Health Emergency (ECDC PHE) team, the World Association for Infectious Diseases and Immunological Disorders (WAidid), the Global Tuberculosis Network (GTN), and members of the European Society of Clinical Microbiology and Infectious Diseases (ESCMID) Study Group for Mycobacterial Infections (ESGMYC).

\section{Methods}

We performed a rapid and nonsystematic search of the literature using the key words "COVID-19", "tuberculosis", "viral infection", "HIV infection", "SARS”, "lung”, “immunology", “diagnosis", "prevention”, "infection control" and "workplace" to identify a minimum set of references from an electronic database

Affiliations: ${ }^{1}$ Dept of Medicine, Yong Loo Lin School of Medicine, National University of Singapore, Singapore. ${ }^{2}$ Institute for Health Innovation and Technology (iHealthtech), National University of Singapore, Singapore. ${ }^{3}$ Servizio di Epidemiologia Clinica delle Malattie Respiratorie, Istituti Clinici Scientifici Maugeri IRCCS, Tradate, Italy. ${ }^{4}$ Centre for Multidisciplinary Research in Health Science, University of Milan, Milan, Italy. ${ }^{5}$ Global Studies Institute, University of Geneva, Geneva, Switzerland. ${ }^{6}$ Dept of Public Health Sciences, Penn State College of Medicine, Hershey, PA, USA. ${ }^{7}$ Clinical Epidemiology and Medical Statistics Unit, Dept of Medical, Surgical and Experimental Sciences, University of Sassari, Sassari, Italy. ${ }^{8}$ Sydney Pharmacy School, University of Sydney, Sydney, Australia. ${ }^{9}$ Westmead Hospital, Sydney, Australia. ${ }^{10}$ Marie Bashir Institute of Infectious Diseases and Biosecurity, University of Sydney, Sydney, Australia. ${ }^{11}$ Blizard Institute, Barts and The London School of Medicine and Dentistry, Queen Mary University of London, London, UK. ${ }^{12}$ Division of Infection, Royal London Hospital, Barts Health NHS Trust, London, UK. ${ }^{13}$ Public Health Emergency Team, European Centre for Disease Prevention and Control, Stockholm, Sweden. ${ }^{14}$ Translational Research Unit, Epidemiology and Preclinical Research Dept, “L. Spallanzani” National Institute for Infectious Diseases (INMI), IRCCS, Rome, Italy. ${ }^{15}$ AP-HP-Lariboisiere, Bacteriologie, Laboratory Associated to the National Reference Centre for Mycobacteria, IAME UMR1137, INSERM, University of Paris, Paris, France. ${ }^{16}$ Laboratory of Virology, Epidemiology and Preclinical Research Dept, “L. Spallanzani” National Institute for Infectious Diseases (INMI), IRCCS, Rome, Italy. ${ }^{17}$ Emerging Bacterial Pathogens Unit, IRCCS San Raffaele Scientific Institute, Milan, Italy. ${ }^{18}$ Public Health Consulting Group, Lugano, Switzerland. ${ }^{19}$ Università Cattolica Sacro Cuore, Roma, Italy. ${ }^{20}$ Mater Olbia Hospital, Olbia, Italy. ${ }^{21}$ Pediatric Clinic, Pietro Barilla Children's Hospital, University of Parma, Parma, Italy. ${ }^{22}$ National Health Service, London, UK. ${ }^{23}$ St George's, University of London, London, UK. ${ }^{24}$ Tuberculosis Control Unit, Dept of Respiratory and Critical Care Medicine, Tan Tock Seng Hospital, Singapore. ${ }^{25}$ Scientific Direction, “L. Spallanzani” National Institute for Infectious Diseases (INMI), IRCCS, Rome, Italy. ${ }^{26}$ School of Medicine, University of Zagreb and Clinic for Respiratory Diseases, University Hospital Center Zagreb, Zagreb, Croatia. ${ }^{27}$ National Centre for Infectious Diseases, Singapore. ${ }^{28}$ Hong Kong Tuberculosis, Chest and Heart Diseases Association, Wanchai, Hong Kong, China. ${ }^{29}$ Dept of Clinical Pharmacy and Pharmacology, University Medical Center Groningen, University of Groningen, Groningen, The Netherlands. ${ }^{30}$ Scientific Direction, Istituti Clinici Scientifici Maugeri IRCCS, Pavia, Italy. ${ }^{31}$ Dept of Infectious Diseases, Galliera Hospital, Genova, Italy. ${ }^{32}$ Dept of Infectious Diseases, Bellvitge University Hospital-Bellvitge Biomedical Research Institute (IDIBELL), L'Hospitalet de Llobregat, Barcelona, Spain. ${ }^{33}$ Dept of Clinical Science, University of Barcelona, L'Hospitalet de Llobregat, Barcelona, Spain. ${ }^{34}$ Division of Pulmonary Rehabilitation, Istituti Clinici Scientifici Maugeri, IRCCS, Tradate, Italy. ${ }^{35}$ Dept of Medicine and Surgery, Respiratory Diseases, University of Insubria, Varese-Como, Italy. ${ }^{36}$ Radboudumc Center for Infectious Diseases, Radboud Institute for Health Sciences, Radboudumc, Nijmegen, The Netherlands. ${ }^{37}$ Centre for Tropical Medicine and Global Health, Nuffield Dept of Medicine, University of Oxford, Oxford, UK. ${ }^{38} \mathrm{Global}$ Health and Tropical Medicine, Institute of Hygiene and Tropical Medicine, NOVA University of Lisbon, Lisbon, Portugal. ${ }^{39}$ TB Competence Centre, Swiss Lung Association, Berne, Switzerland. ${ }^{40}$ Dept of Infection, Division of Infection and Immunity, University College London and NIHR Biomedical Research Centre, UCL Hospitals NHS Foundation Trust, London, UK. ${ }^{41}$ Saint Camillus International University of Health and Medical Sciences, Rome, Italy. ${ }^{41}$ These authors contributed equally. ${ }^{42}$ Members of ESGMYC. ${ }^{43}$ European Centre for Disease Prevention and Control Public Health Emergency team co-authors.

Correspondence: Delia Goletti, Translational Research Unit, Epidemiology and Preclinical Research Dept, “L. Spallanzani” National Institute for Infectious Diseases (INMI), IRCCS, Via Portuense 292, 00149, Rome, Italy. E-mail: delia.golettidinmi.it

Correspondence: Giovanni Battista Migliori, Servizio di Epidemiologia Clinica delle Malattie Respiratorie, Istituti Clinici Scientifici Maugeri IRCCS, Via Roncaccio 16, Tradate, Varese, 21049, Italy. E-mail: giovannibattista.miglioridicsmaugeri.it 
(PubMed), existing guidelines on TB, viral diseases and airborne diseases, and grey literature from their inception until April 29, 2020. Guidelines were retrieved from the websites of the main international health-related centres, whereas grey literature was accessed using the Google search engine.

A writing committee composed of international experts was established, including the ECDC PHE team, WAidid, GTN and ESGMYC.

Consensus on the content was achieved after multiple rounds of revisions between the writing committee and the larger group of experts [2].

A Delphi process involving the core group of authors, excluding the ECDC PHE team, identified the areas requiring review/consensus, followed by a second round to refine the definitive consensus elements.

As the review was not aimed at duplicating World Health Organization (WHO), ECDC and other existing guidelines, the GRADE (Grading of Recommendations, Assessment, Development and Evaluations) methodology was not used and no formal recommendations are provided. The available information on prevention, diagnosis and treatment of TB and pulmonary viral diseases was selected by the experts and summarised, and country examples were provided to critically discuss the public health response.

\section{Viral diseases of the lung Epidemiology}

Viral respiratory infections are a major public health concern due to the capacity of viruses to spread from person to person directly via aerosols/droplet nuclei, small droplets or virus-laden secretions from larger droplets, or indirectly by contact with contaminated surfaces [3]. Large respiratory droplets are generated primarily during coughing, sneezing and talking, and during procedures such as suctioning and bronchoscopy, which can also generate droplet nuclei. Transmission occurs when droplets containing microorganisms from an infected person are expelled a short distance through the air and deposited on another individual's conjunctivae, nasal mucosa or mouth. Large droplets fall quickly onto surfaces close to the infected person, increasing the risk of contact transmission. Moreover, viral infections can also be transmitted via aerosol particles of small size $(<5-10 \mu \mathrm{m})$ which may be infectious at a distance of several metres [4-7]. Recent evidence suggests the SARS coronavirus 2 (SARS-CoV-2) virus may be present in exhaled air while talking and breathing [8], being detected for several hours on different surfaces [9].

Respiratory infections can be classified by the causative virus (e.g. influenza) or clinically according to the clinical syndrome. Symptoms may include fever, nonproductive cough, coryza, sneezing, dyspnoea, myalgia, fatigue and nonexudative pharyngitis [10].

The clinical spectrum can encompass asymptomatic infection, upper respiratory tract infection and lower respiratory tract infection that can result in pneumonia or acute respiratory distress [11], and systemic infection [12].

The severity of viral respiratory illness varies widely and severe disease is more likely in older patients with or without comorbidities. Infants may have more severe disease for some organisms. Morbidity may result directly from viral infection, or may be due to exacerbation of other chronic medical conditions or bacterial superinfection $[13,14]$.

The spread of respiratory virus infections varies between countries and regions, depending on differences in population, geography, climate, immunisation coverage and socioeconomic status [15-17].

\section{Immunology}

The first line of defence against respiratory viral infections includes intrinsic defences such as mucus and antiviral peptides. When these are circumvented, viruses enter the epithelial cells by recognising viral components via Toll-like receptors and intracellular receptors (figure 1) [18], and initiate the inflammatory response. Innate cells such as dendritic cells, alveolar macrophages, natural killer cells and neutrophils are recruited. All these cells promote an antiviral response and are important for the establishment of adaptive responses. Concurrently, these inflammatory cells may be important in driving innate immune-mediated tissue damage, a process which also occurs in TB [19].

T-cells contribute to the generation of the B-cell response and cell-mediated immunity leading to viral clearance. In particular, B-cells produce antibodies that may neutralise the respiratory viruses directly by binding to viral surface proteins or activating the complement cascade (figure 1) [20, 21]. T-follicular helper cells, a specialised subset of $\mathrm{CD}^{+} \mathrm{T}$-cells, play a critical role in protective immunity helping B-cells produce antibodies against foreign pathogens [22]. Viral clearance is also mediated by $\mathrm{CD} 8^{+}$-specific T-cells with cytolytic activity. The protective antiviral T-cell response is a T-helper cell type 1 (Th1) response mainly mediated through interferon (IFN) $-\gamma$ production [22-25]. Moreover, to prevent lung 
tissue damage, all these responses are finely modulated; regulatory mechanisms adopted by T-cells such as cytokine secretion, upregulation of inhibitory receptors [26] or expansion of the T-regulatory cell subset lead to a balance between tissue damage and clearance of the virus. The immune systems of neonates, infants, children and adults are different, both in their composition and functional responsiveness to infectious diseases $[27,28]$.

Regarding the response to Mycobacterium tuberculosis, after mycobacterial dissemination to the lymph nodes, dendritic cells present bacterial antigens to T-cells and prime them [29, 30]. Priming occurs around 10 days post-infection in the mediastinal lymph nodes, and is followed by generation of effector T-cells [31] and Th1 CD4 ${ }^{+}$T-cells that lead to the formation of granulomas. Granulomas are organised structures where T-cells and B-cells surround innate immune cells (macrophages and neutrophils) with a fibrotic capsule to generate a hypoxic environment to prevent $M$. tuberculosis growth [32], with hypoxia potentially worsening tissue destruction in TB [33]. CD4 Th1 host responses are crucial [34], especially at the beginning for TB control $[35,36]$. Regarding the CD8 T-cell component, mouse studies have revealed a relatively smaller role of $\mathrm{CD}^{+} \mathrm{T}$-cells in protection against $M$. tuberculosis infection [37], and an even smaller contribution of B-cells and humoral immunity [38]. Differently, in human studies, $M$. tuberculosis-specific CD8 T-cells have been associated with active TB [39-44], both in HIV-uninfected and -infected patients [35, 42,45], and in response to recent infections [43, 44]. Increased CD8 T-cell response is associated with $M$. tuberculosis load and longitudinal studies have shown a decrease of this CD8 T-cell response during anti-TB treatment [39, 40]. It has been shown that the cells are differently modulated over the course of TB disease, suggesting a role in TB pathogenesis that is not yet fully elucidated [46-48].

\section{Bacille Calmette-Guérin vaccination as a potential intervention against COVID-19}

Bacille Calmette-Guérin (BCG), the current vaccine against $\mathrm{TB}$, has important protective effects against other infections. In randomised trials, BCG reduced infant mortality by around 40\% [49] and respiratory infections other than TB by $70 \%$ in adolescents [50]. These "nonspecific effects" of BCG vaccination are explained by epigenetic and metabolic reprogramming of innate immune cells, a process termed "trained immunity" [51]. Clinical evidence suggests that BCG may protect against viruses [52], and BCG-vaccinated healthy adults re-challenged with live yellow fever vaccine showed improved antiviral immunity and decreased viral loads [53]. In mice, BCG vaccination protects against influenza A, lowering viral replication and lung injury $[54,55]$.

A recent ecological analysis suggested that BCG vaccination may also protect against COVID-19 [56]. Countries without universal policies of BCG vaccination (e.g. Italy, the Netherlands and the USA) seem more severely affected by COVID-19 compared with countries with universal BCG policies. However, such ecological studies that relate country aggregate and individual data should be interpreted with caution. Also, COVID-19 has shown a recent increase since publication of the analysis [56] in low- and middle-income countries and may still be underreported, confounders such as age were not taken into account, and variable BCG policies over time affect individual BCG coverage [57-59]. Several large randomised controlled trials (RCTs) currently evaluating the effect of BCG vaccination against COVID-19 in thousands of healthcare workers and elderly, in the Netherlands, Australia and other countries, will provide evidence to support or refute BCG as a cheap and rapidly scalable preventive measure against COVID-19 and other viral respiratory infections.

\section{Influenza H1N1 and lung disease}

The two most serious impacts of influenza virus on the lung are the development of pneumonia and exacerbation of pre-existing pulmonary disease [60]. Such events seem rare and variable during most seasonal influenza periods, but may be more frequent and severe in pandemics. During the 2018-2019 season, there was an estimated 32 million cases of influenza resulting in 32000 deaths in the USA [61]. H1N1, the virus behind the 1918 and 2009 pandemics, appears to cause more rapid and severe pneumonia than other strains, with higher rates of bacterial superinfection [62]. H1N1 also affects the paediatric population $[63,64]$.

Primary viral pneumonia is characterised by rapid onset of nonproductive cough, headache, myalgias, dyspnoea, tachypnoea, hypoxia and ground-glass opacities on computed tomography (CT) scans. Secondary bacterial pneumonia, which may occur concurrently or following the development of viral pneumonia, is a frequent complication. Bacterial superinfection occurs through direct damage of the respiratory epithelium with modification of local and systemic immune defence. Bacterial superinfection, mainly due to Staphylococcus aureus and Streptococcus pneumoniae [65], is reported in 20-47\% of influenza patients admitted to intensive care units (ICUs). Its global prevalence varies between $0.1 \%$ and $10 \%$ according to historical surveys, and $1.59 \%$ according to a recent Korean survey during the 2009 


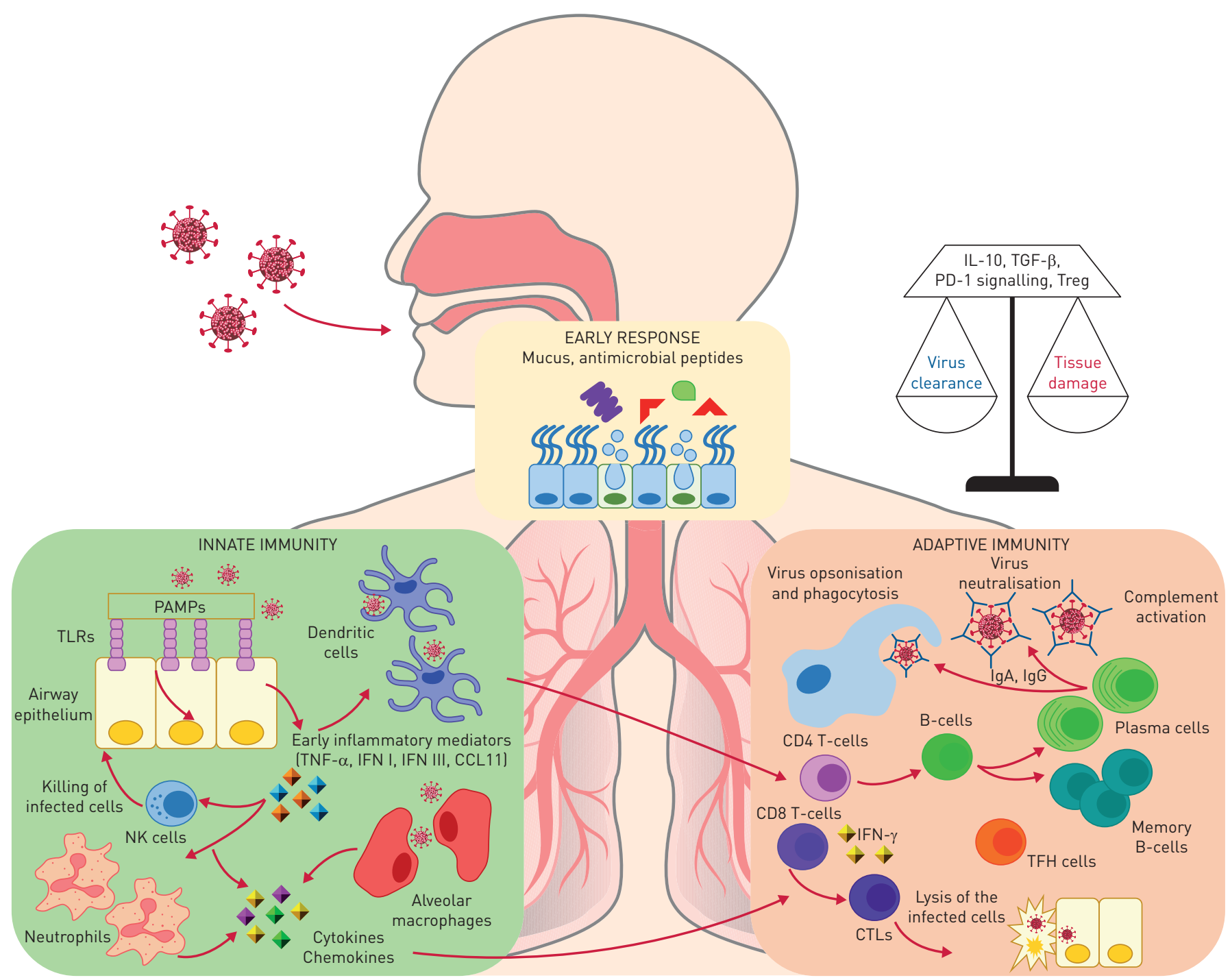

FIGURE 1 The lungs and gut are exposed to environmental substances and pathogens. The early protection response to respiratory viruses includes mucus, surfactants and antiviral peptides that can prevent initial attachment and viral entry. Respiratory viruses enter via the respiratory epithelium. Epithelial cells have a key role in initiating the immune response by recognising viral components (pathogen-associated molecular patterns (PAMPs)) via Toll-like receptors (TLRs) and intracellular receptors. These cellular sensors trigger a signalling cascade resulting in the upregulation of type I and III interferon (IFN) and the inflammatory response. This leads to differentiation of dendritic cells that mediate the induction of the adaptive immunity and promote the recruitment of innate immunity cells, in particular neutrophils and natural killer (NK) cells. NK cells have the ability to kill virus-infected cells via perforin-granzyme-dependent mechanisms or by the Fas-Fas ligand pathway. Moreover, alveolar macrophages, recruited monocytes and macrophages as well as dendritic cells pick pathogen components and contribute to the immune response. All of these cells produce cytokines and chemokines that are important for the establishment of the adaptive responses and of the antiviral state. The adaptive response to respiratory viruses is mediated by both T-and B-cell compartments. T-cells contribute to the generation of the B-cell response. B-cells produce antibodies that may neutralise the respiratory viruses directly by binding to viral surface proteins that are essential for entry of the virus into host cells or through the ligation of Fc receptors to trigger the complement cascade and antibody-dependent cell-mediated cytotoxicity. Antibodies are in the form of IgA, mainly in the upper respiratory tract, or IgG, in the lower respiratory tract. Viral clearance is also mediated by $\mathrm{CD}^{+}$-specific T-cells with cytolytic activity. The protective antiviral T-cell response is mainly mediated by IFN- $\gamma$ production and is therefore biased toward a T-helper cell (Th) 1 response, whereas other T-cell subsets such as Th2 cells and Th17 cells play a minor role and they may be responsible for lung tissue damage. Moreover, regulatory mechanisms adopted by T-cells such as interleukin (IL)-10 secretion, or upregulation of inhibitory receptors such as programmed cell death protein 1 (PD-1) or expansion of the T-regulatory (Treg) cell subsets, work to balance tissue damage and viral clearance. TNF: tumour necrosis factor; CTL: cytotoxic T-lymphocyte; TFH: T-follicular helper; TGF: transforming growth factor.

influenza $\mathrm{A}(\mathrm{H} 1 \mathrm{N1}) \mathrm{pdm} / 09$ pandemic [66]. Acute respiratory distress syndrome (ARDS) and bacterial superinfection are two distinct clinical-pathological syndromes which have been described in the influenza pandemia of 1918 by Morens and FAUCI [67]. ARDS was responsible for $10-15 \%$ of the fatal cases, while bacterial superinfection, with poorer prognosis with $85-90 \%$ fatal cases, manifests as acute bronchopneumonia, with pathogenic bacteria cultured on autopsy $[60,62,68]$. 
Other viral infections and lung disease (SARS and MERS)

In recent decades, previously unknown zoonotic respiratory tract infections with epidemic potential such as SARS and MERS have emerged. Human coronaviruses are usually classified into low and highly pathogenic [69]. The low pathogenic coronaviruses infect the upper respiratory tract and cause "flu-like" mild respiratory illness, while highly pathogenic coronaviruses (SARS and MERS) predominantly infect the lower airways, often causing fatal pneumonia [69].

Severe coronavirus pneumonia is often associated with rapid virus replication, massive inflammatory cell infiltration and elevated pro-inflammatory cytokine/chemokine responses producing acute lung injury and ARDS. Recent studies in experimentally infected animals strongly suggest a crucial role for virus-induced immunopathological events in causing fatal pneumonia following coronavirus infection [69].

High initial viral titres in the airways, age and comorbidities (e.g. hypertension, diabetes, obesity, heart failure, renal failure, etc.) are associated with worse outcomes [70-74].

SARS-CoV, which enters the human cell via the angiotensin-converting enzyme 2 receptor [75], usually presents with three phases [76]: 1) rapid viral replication with fever, cough and other nonspecific symptoms, disappearing in a few days; 2) high fever, hypoxaemia and progression to pneumonia-like symptoms, despite a progressive decline of viral replication; and 3) development of ARDS in around 20\% of patients with mortality [77-79].

MERS, which enters the human cell via the dipeptidyl peptidase-4 receptor [80], usually starts with flu-like symptoms: fever, sore throat, nonproductive cough, myalgia, shortness of breath and dyspnoea, often progressing to pneumonia (ICU admission necessary) [73, 81]. It can also cause gastrointestinal symptoms (abdominal pain, vomiting and diarrhoea).

\section{COVID-19 and lung disease}

According to a recent report from China, COVID-19, the disease caused by SARS-CoV-2, is characterised by three clinical patterns: absence or paucity of symptoms, mild-to-moderate disease and severe pneumonia requiring admission to the ICU [82]. Dyspnoea develops after a median time of 8 days from illness onset, with a median time to ICU admission of 5 days. Up to $20 \%$ of patients require transfer to the ICU $[83,84]$, with consequent overwhelming of healthcare capacity. The evidence suggests that while $25 \%$ of COVID-19 patients have comorbidities including chronic obstructive pulmonary disease (COPD), diabetes mellitus, hypertension, coronary heart disease, cerebrovascular disease and malignancies, the proportion is more than $90 \%$ among those who die [83-87]. In children, COVID-19 symptoms are usually milder with better outcome than adults [88-92]. Frequency of clinical presentations and outcome appear different in Europe, with higher lethality compared with China, although this figure may change overtime due to better estimation of the total number of infections [93]. Besides virological diagnosis, imaging by chest radiography, ultrasound and CT are important for diagnosis and management. Main CT abnormalities include ground-glass opacity and consolidation [94]. The combination of CT scan findings, respiratory parameters (peripheral capillary oxygen saturation and arterial oxygen tension/inspiratory oxygen fraction ratio) and blood tests (C-reactive proteins, lymphocyte count, lactate dehydrogenase, triglycerides, ferritin, fibrinogen, D-dimer and interleukin (IL)-6) [84, 95] are important features to identify those at highest risk for ICU transfer. Lungs of dead COVID-19 patients showed oedema, proteinaceous exudate, focal reactive hyperplasia of pneumocytes with patchy inflammatory cellular infiltration and multinucleated giant cells with fibroblastic plugs in airspaces [96, 97]. A recent study reported autopsy cases contained diffuse alveolar damage with mononuclear response $\left(\mathrm{CD} 4^{+}\right.$aggregates) surrounding thrombosed vessels, in the presence of associated haemorrhages [98-100].

\section{HIV and lung disease}

The spectrum of HIV-associated pulmonary diseases is broad and the lungs are one of the most frequently affected organ systems in HIV-infected persons regardless of age [101]. The absolute CD4 T-cell count, used as a surrogate marker of immunodeficiency, is important in guiding the aetiological evaluation of lung infections [102]. Pulmonary TB infection and reactivation are more likely with a CD4 count below 500 cells $\cdot \mathrm{mL}^{-1}$. Opportunistic infections, Pneumocystis jirovecii, bacterial infections, Kaposi sarcoma and extrapulmonary/disseminated forms of TB occur mainly in patients with CD4 T-cell counts below 200 cells $\cdot \mathrm{mL}^{-1}$. Cytomegalovirus infection, Mycobacterium avium complex and aspergillosis usually occur at CD4 counts below 50 cells $\cdot \mathrm{mL}^{-1}$. Risk factors to consider are the geographical origin that predisposes to specific disease (e.g. TB, coccidioidomycosis, paragonimiasis and histoplasmosis), adherence to antiretroviral therapy, prescription of $P$. jirovecii prophylaxis and presence of comorbidities. Community-acquired bacterial pneumonia occurs at all stages of HIV infection, but is more frequent in patients with profound CD4 T-cell depletion and decreases with antiretroviral therapy. Community-acquired pneumonia accounts for $35-50 \%$ of all hospital admission cases due to respiratory failure and is the main reason for ICU admission [103]. 


\section{TB and respiratory viral diseases $T B$ and influenza}

The association of TB and influenza could be bidirectional: TB may increase the susceptibility to influenza and the risk of complications, and influenza may increase the susceptibility to TB. The susceptibility to influenza appears to be greater in patients with pre-existing pulmonary disease (e.g. asthma and COPD). As a large proportion of post-TB treatment patients have long-term functional impairment, mainly COPD, which can be severe $[104,105]$, patients with such pulmonary sequelae may be predisposed and more susceptible to influenza infection and its complications, including mortality [106]. Furthermore, the temporary immunosuppression induced by $\mathrm{TB}$ may increase the susceptibility of patients to influenza infection. An excess mortality associated with influenza has been described among TB patients in South Africa [107]. TB patients have a similar prevalence of viral and bacterial co-infection as their household contacts, but TB patients often have more severe disease if they are co-infected [108].

As early as 1919, the occurrence of TB among patients surviving influenza or pneumonia, but without clear distinction between both diseases, was reported [109]. Influenza induces a temporary increase in the susceptibility to bacterial infections, exemplified by the frequent occurrence of bacterial pneumonia following viral pneumonitis [110]. Because influenza impairs the immune response, it may be expected that influenza could also promote the development of active TB among patients with latent TB infection (LTBI) [111]; however, the occurrence of TB may occur much later than the occurrence of influenza, thus making the temporal association difficult to demonstrate. There was an excess mortality from pulmonary TB during the influenza pandemics of 1889 and 1918 in Switzerland [112]. It has also been reported that summer influenza epidemics in Wuhan, China, may have contributed to the increase in reported TB cases [113]. Conversely, a report from Thailand did not demonstrate a worse outcome for patients with concurrent influenza and TB [114], and another report from Indonesia did not demonstrate a correlation between antibodies against influenza and the presence of TB, but there was an association between the level of antibody titres against influenza virus and the stage of $\mathrm{TB}$ [115]. Interestingly, influenza vaccination was reported to be a protective factor against TB in elderly persons in Taiwan [116]. The exact impact of concurrent influenza and TB remains uncertain.

\section{TB and HIV}

The interaction between TB and HIV is well known. Without antiretroviral treatment, the risk of LTBI progressing to active TB disease in people living with HIV and AIDS (PLWHA) is greater than in immunocompetent hosts. In PLWHA, the risk of developing TB is of the order of $10 \%$ per year $[117,118]$. This elevated risk is behind the WHO recommendation of TB screening and/or preventive treatment for all PLWHA $[119,120]$. New regimens as short as 1 month (daily rifapentine plus isoniazid) to 3 months (weekly rifapentine plus isoniazid) were recently recommended by the WHO, and are well tolerated and effective [119, 120]. Important programmatic implications for collaboration between TB and HIV/AIDS services exist: TB services should test for HIV (allowing treatment of TB patients with antiretrovirals and cotrimoxazole preventive therapy in patients with HIV/TB co-infection) and HIV/AIDS services should screen for LTBI, using the tuberculin skin test (TST) or IFN- $\gamma$ release assay (IGRA), and initiate prompt treatment of TB or LTBI in PLWHA $[119,120]$. Based on this rationale (two diseases, one patient), WHO promotes TB/HIV collaborative activities focused on three main pillars [121]: 1) establish TB/HIV collaborative mechanisms, 2) decrease the burden of TB among PLWHA and 3) decrease the burden of HIV among TB patients. Moreover, testing for other infections in addition to HIV in TB clinics may be indicated during epidemics and pandemics.

\section{TB, SARS and MERS}

TB co-infection with SARS is rare. A study of 83 patients with SARS found three patients with TB co-infection, where one patient with SARS subsequently developed TB, while the other two had TB and then developed SARS [122]. All three patients were on steroid therapy, which may have decreased viraland/or TB-specific immunity and increased the risk of co-infection. In a different cohort of 236 SARS patients, two were diagnosed with pulmonary TB [123]. The development of TB in the presence of SARS may be due to $\mathrm{CD} 4$ lymphopenia during the viral infection [124], as $\mathrm{CD}^{+} \mathrm{T}$-cells are crucial for TB-specific immunity [41, 125-129]. Lastly, one TB patient developed SARS co-infection because of a wrong admission to a cohort of SARS patients [130]. This highlights the importance of remaining vigilant to other communicable diseases, including TB, when epidemic or pandemic infections dominate media headlines [131]. TB with MERS-CoV co-infection is also rare. A report of 295 MERS-CoV patients found two TB patients [132], although it was unclear which the initial infection was.

\section{TB and COVID-19}

There may be interaction between COVID-19 and TB [133], but long-term observations are lacking [134]. Only two studies have investigated the interactions so far. In the first ever cohort of 49 patients from eight 
countries, COVID-19 was diagnosed before, simultaneously or after TB [135]. In the second study including 69 patients, mortality was investigated [136]. In a separate anecdotal report, Liu et al. [133] reported an increased prevalence of LTBI in patients with severe COVID-19 infection and concluded that infection with $M$. tuberculosis may influence the progression and outcome of COVID-19. Evidence on the interactions between TB and COVID-19 is needed.

\section{Respiratory viral diseases and TB in the elderly, prisoners and other vulnerable groups}

The elderly (aged 65 years old or older), prisoners and other vulnerable groups such as forced migrants may reside in high-density communal settings which can perpetuate rapid infectious disease transmission during an epidemic or pandemic. Immunosenescence is an additional risk factor in the elderly [137].

Clinical presentation of these infections in the elderly can be subtle, with atypical manifestation such as delirium, and may present with complications. SARS and COVID-19 respiratory failure are well documented in the elderly $[138,139]$. Conversely to influenza A (H1N1)pdm/09, a study of 4962 patients found elderly patients had less risk of respiratory failure, ICU admission or mechanical ventilation [140]. For TB, old age is a risk factor for active TB with poorer treatment outcomes $[1,141]$, while TB symptoms are indistinguishable from symptoms of malignancies. Moreover, the elderly may also suffer from abnormal drug absorption and/or drug toxicities due to polypharmacy for comorbidities. Similarly, immunocompromised and pregnant women may also present with complications including respiratory failure when infected with pandemic H1N1 influenza or TB [142-144].

Diagnostic tests for each group depend on available resources and on accessibility, which may be limited to none for the homeless and the incarcerated, although there should be equity in the availability of testing and treatment. The elderly may further have technical difficulties in providing quality respiratory samples for testing, such as for $\mathrm{TB}$, when they have an impaired cough response. A poor quality respiratory sample inevitably delays diagnosis and contact tracing efforts.

Treatment and management of viral infections and TB includes prompt isolation of presumptive cases and of microbiologically confirmed cases depending on available resources, or even controlled release of prisoners [145]. This is part of the comprehensive strategy to mitigate transmission in nursing homes for the elderly, in refugee camps and in correctional facilities [146]. Prognosis of TB, SARS and COVID-19 tends to be worse, with higher mortality in the elderly [77, 138, 147].

\section{Diagnostic challenges in viral diseases and TB}

For prompt diagnosis of viruses causing severe acute respiratory infections [148], such as SARS-CoV, MERS-CoV and SARS-CoV-2 [149-152], and differentiation from other common bacterial infections, a strategic laboratory approach is needed. This approach requires integrating conventional virology assays, molecular platforms combining nucleic acid extraction and PCR or real-time PCR, and rapid molecular tests (RDTs) used in point-of-care minilabs (table 1). Positive results using single or multiplex RDTs may lead to adequate cohorting and management of infected patients [153]. Negative results are often less conclusive because of a lack of sensitivity and nonstandardised collection of specimens. Using metagenomic next-generation sequencing, pathogens not included in the tests can be detected including both known and novel viruses. Genomic data provides information on virulence genes [154], resistance mutations and clusters using phylogenetic approaches $[155,156]$. Specific antibody detection remains useful for seroprevalence studies in selected populations and in vaccine studies. The recurrence of old pathogens and emergence of new pathogens like SARS-CoV-2 underlines the importance of worldwide virus surveillance systems [157]. For this purpose, developing protein microarrays to respiratory virus serology is useful [153].

Diagnosis of active TB relies on direct detection of $M$. tuberculosis, most often in respiratory specimens. Although culture remains the "gold standard" in terms of sensitivity and specificity, effective molecular assays to detect $M$. tuberculosis DNA are also used on platforms and in point-of-care tests [158]. Moreover, these M. tuberculosis molecular assays can detect mutations associated with resistance, rapidly detecting multidrug-resistant TB strains resistant to rifampin and isoniazid, allowing appropriate therapies and curbing transmission of these strains [159]. Testing immune memory to a previous TB exposure (i.e. LTBI), performed with TSTs and IGRAs, cannot be used as a surrogate for protection, but identifies persons who have been previously infected and can be useful to guide the TB diagnostic algorithm [160].

The massive use of molecular assays to diagnose COVID-19 introduced similar molecular platforms that could be used for detecting pathogens in respiratory specimens. The challenge lies in sample processing and RNA/DNA extraction protocols rather than cross-reactivity resulting in false-positive results. This is an opportunity to strengthen the diagnostic potential of microbiological laboratories, producing an 
TABLE 1 Performance characteristics of diagnostic approaches to respiratory infection

\begin{tabular}{|c|c|c|c|c|c|c|c|c|c|c|}
\hline & \multicolumn{5}{|c|}{ Respiratory viruses } & \multicolumn{5}{|c|}{ Mycobacterium tuberculosis complex } \\
\hline & Sensitivity & Specificity & $\begin{array}{c}\text { Time } \\
\text { to } \\
\text { result }\end{array}$ & $\begin{array}{c}\text { User } \\
\text { friendly }\end{array}$ & $\begin{array}{c}\text { Unknown or } \\
\text { uncommon } \\
\text { viruses }\end{array}$ & Sensitivity & Specificity & $\begin{array}{l}\text { Time } \\
\text { saving }\end{array}$ & $\begin{array}{l}\text { User } \\
\text { friendly }\end{array}$ & $\begin{array}{l}\text { Drug } \\
\text { susceptibility } \\
\text { testing }\end{array}$ \\
\hline \multicolumn{11}{|l|}{$\begin{array}{l}\text { Molecular } \\
\text { diagnosis }\end{array}$} \\
\hline Manual NAAT & +++ & +++ & - & - & - & +++ & ++ & + & - & + \\
\hline POCT-NAAT & + & ++ & +++ & +++ & - & +++ & +++ & +++ & + & + \\
\hline NGS & - & - & - & - & ++ & + & +++ & - & - & +++ \\
\hline Microscopy $^{+}$ & - & ++ & - & - & - & + & + & ++ & + & - \\
\hline Culture ${ }^{\S}$ & - & + & - & - & + & +++ & +++ & - & - & +++ \\
\hline \multicolumn{11}{|l|}{ Antigen detection } \\
\hline РOCT & - & + & +++ & ++ & - & $+^{f}$ & ++ & +++ & +++ & NA \\
\hline IGRA & ES & ES & - & - & - & ++ & + & ++ & + & NA \\
\hline TST & NA & NA & NA & NA & NA & ++ & + & ++ & ++ & NA \\
\hline \multicolumn{11}{|c|}{$\begin{array}{l}\text { Quantitation: -: very poor; }+ \text { : poor; }++: \text { good; }+++ \text { : excellent. NAAT: nucleic acid amplification test; POCT: point-of-care test; NGS: } \\
\text { next-generation sequencing; NA: not applicable; NRU: not routinely used; ES: experimental settings only; IGRA: interferon- } \gamma \text { release assay; } \\
\text { TST: tuberculin skin test (Mantoux test); TB: tuberculosis. \#: considering only the time of the procedure }<2 \mathrm{~h} \text {; }{ }^{\uparrow} \text { : metagenomics and } \\
\text { whole-genome sequencing; }{ }^{+} \text {: immunofluorescence microscopy on respiratory samples to detect the most common viruses, or Ziehl-Neelsen } \\
\text { or auramine/rhodamine staining to detect acid-fast bacilli; }{ }^{\S} \text { : viral culture established in several eukaryotic cell lines and mycobacterial culture } \\
\text { in liquid or solid media; }{ }^{f} \text { : the only approved antigen POCT for TB detects lipoarabinomannan in urine samples and has been licensed to } \\
\text { diagnose TB in HIV-infected patients and to monitor therapy. }\end{array}$} \\
\hline
\end{tabular}

invaluable asset to improve diagnosis against other infections including TB. At the same time, the expertise, tools and networks developed for TB diagnosis could aid the rapid implementation of molecular diagnosis of COVID-19 and other viral infections. Tests (lateral flow assay and ELISA based) to rapidly detect antigens in swabs or respiratory secretions and to determine serological evidence of recent and past infection and evidence of neutralising antibodies are currently being evaluated.

\section{Impact of new, potential and existing drugs for viral diseases and COVID-19 on TB therapy}

$80 \%$ of COVID-19 cases are generally mild and self-limiting, and may require no treatment. Lacking licensed drugs for SARS-CoV-2, therapeutic approaches in severely ill patients are limited to supportive care and empirical use of antibiotics to prevent or treat secondary infections $[84,86,161]$. To provide active treatment for SARS-CoV-2, drugs potentially inhibiting viral replication are of interest (figure 2) [162].

TB patients with COVID-19 may require an adapted therapeutic approach compared with patients without COVID-19. Switching to intravenous anti-TB drugs is recommended for patients in intensive care in order to optimise drug exposure in critically ill patients [163]. Therapeutic solutions for COVID-19 in TB patients need to be considered in the perspective of anti-TB treatment. However, more evidence ideally from clinical trials is necessary.

\section{Lopinavir/ritonavir (Kaletra)}

Lopinavir/ritonavir is a widely studied treatment for COVID-19, although evidence of efficacy is still limited [164]. In non-TB patients, the combination, studied in an open-label RCT, did not show any virological or clinical response compared with standard of care [165]. For the treatment of TB/HIV co-infected patients, lopinavir/ritonavir is not recommended in combination with rifampicin due to cytochrome P450 (CYP) induction. Superboosting of lopinavir/ritonavir by additional ritonavir in children on rifampicin-based TB treatment could be attempted as comparable drug exposure was achieved in situations without rifampicin [166]. Alternatively, rifabutin at a dose of $150 \mathrm{mg}$ once daily has been used in combination with lopinavir/ritonavir [167]. 
Chloroquine phosphate and hydroxychloroquine

Chloroquine and hydroxychloroquine are being evaluated in several clinical trials for therapy and prophylaxis against SARS-CoV-2 following promising in vitro results $[162,168]$. In the absence of results from well-designed clinical studies, clinical benefit is currently unknown [169, 170]. Both drugs have immunomodulatory properties $[171,172]$. Chloroquine has been shown to reduce tumour necrosis factor- $\alpha$ production and receptor-mediated signalling in monocytes, which could prevent SARS-CoV-2-induced severe inflammatory response [173]. TB physicians should be careful when combining these drugs with TB drugs such as moxifloxacin, bedaquiline, delamanid and clofazimine due to the risk of increased QTc prolongation. An ongoing trial was halted due to irregular heart rates and

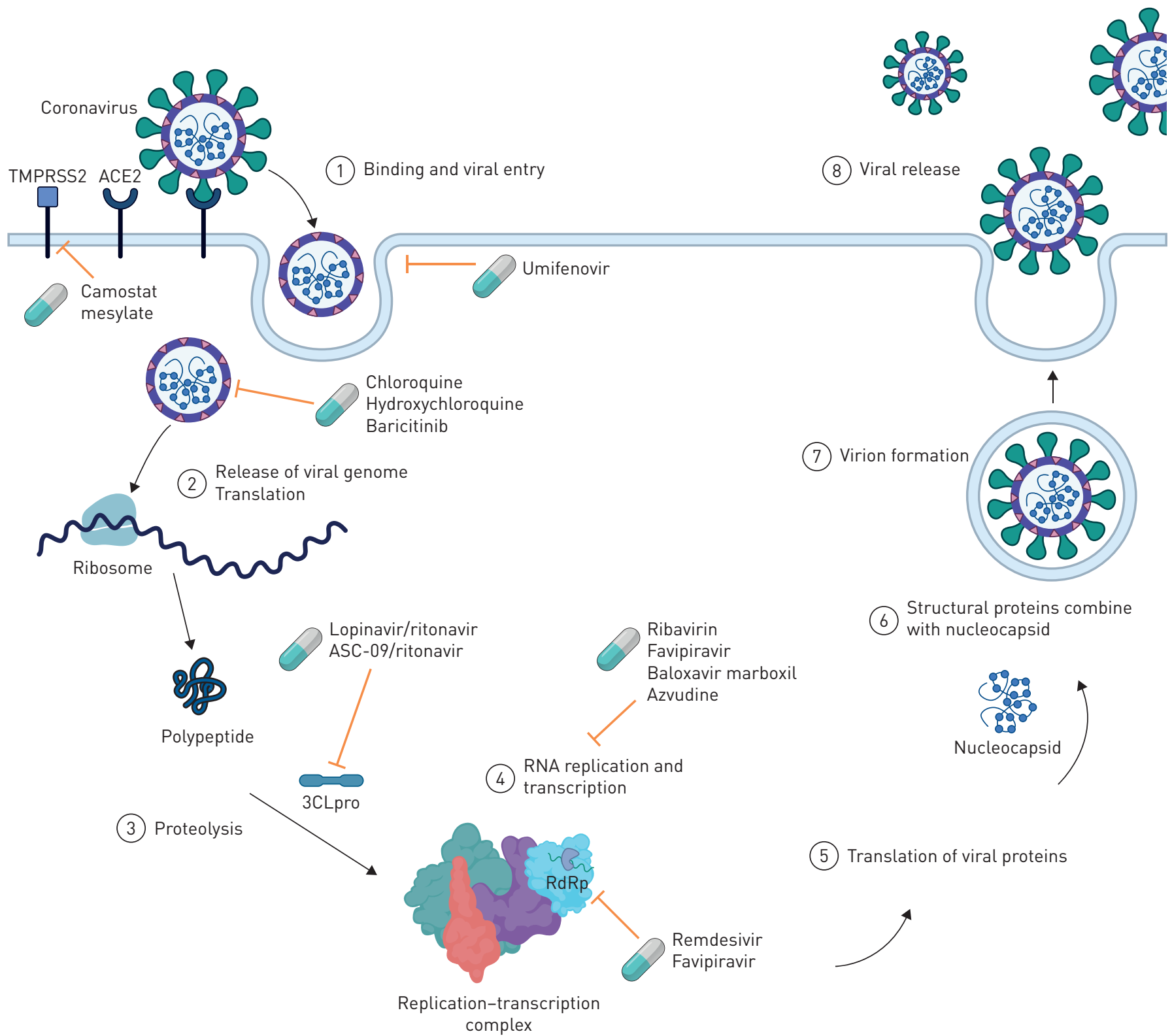

FIGURE 2 Proposed mechanism of action of drugs used for severe acute respiratory syndrome coronavirus 2 (SARS-CoV-2). SARS-CoV-2 can enter the cell through angiotensin-converting enzyme 2 (ACE2) and type II transmembrane serine protease (TMPRSS2). Camostat mesylate acts as an inhibitor of TMPRSS2 and umifenovir can inhibit the viral entry to the cell $[180,228,229]$. Chloroquine, hydroxychloroquine and baricitinib mechanisms of action are not fully understood; however, it is proposed that these drugs affect viral entry. Baricitinib also inhibits the AP-2-associated protein kinase [173, 180, 230]. Lopinavir/ritonavir and ASC-09/ritonavir as protease inhibitors inhibit the proteolysis. Lopinavir/ ritonavir inhibits specifically the proteinase 3CLpro [231]. Ribavirin and favipiravir both have wide antiviral activity and have the potential to inhibit SARS-CoV-2 RNA replication [232-234]. Azvudine, a nucleoside reverse transcriptase inhibitor, also inhibits RNA replication [235]. A probable mechanism of action for baloxavir marboxil is the inhibition of transcription through inhibiting cap-dependent endonuclease [236]. Favipiravir and remdesivir inhibit the RNA-dependent RNA polymerase (RdRp), which results in reduced RNA synthesis [180, 233, 234, 237]. Adapted from "Coronavirus Replication Cycle" (2020; https://app.biorender.com/biorender-templates). 
increased risk of fatal heart arrhythmia [174]. The US Food and Drug Administration (FDA) has also issued a warning on these two drugs [175]. In addition, rifampicin increases chloroquine CYP3A4- and CYP2D6-mediated metabolism to desethylchloroquine and bisdesethylchloroquine [176]. It is unclear whether these metabolites are active against SARS-CoV-2.

\section{Steroids}

Intravenously administered steroids have been recommended for selected non-TB patients with ARDS, preferably in a trial setting $[86,161]$. However, the role of steroids to reduce ARDS in TB patients is limited as data of good quality to support the use of steroids outside the treatment of TB meningitis is scarce [163]. Evidence on the use of steroids in COVID-19 is awaited.

\section{Drug interactions}

Potential drug-drug interactions (DDI) are presented in table 2. The summary of interactions is largely based on evaluations made from pharmacokinetics and toxicity profiles of drugs given alone and comparatively, when co-administered with other drugs in a separate study, in the absence of real dedicated DDI studies. The summary includes effects on drug exposure, monitoring/action and potential mechanisms.

\section{Immunomodulatory drugs}

To reduce the inflammatory response, inhibitors of IL- 1 and IL-6 and the Janus kinase JAK1/JAK2 inhibitor baricitinib are being studied $[177,178]$. Azithromycin may be of potential interest for its immunomodulatory effect [179], although data on its efficacy are lacking and its effect on antimicrobial resistance should be considered. IFNs are being tested because of their stimulatory activities for innate antiviral responses [162].

\section{Novel drugs}

Antiviral candidates such as azvudine, baloxavir marboxil, favipiravir, remdesivir, ribavirin and umifenovir are being tested for COVID-19 (figure 2) [162, 180-182]. Remdesivir is a nucleotide analogue showing in vitro activity against SARS-CoV-2 [182]. Remdesivir is being studied in two large phase 3 RCTs (ClinicalTrials.gov: NCT04252664 and NCT04257656), of which one multicentre trial conducted in Hubei, China, in severe COVID-19 showed no difference in time to clinical improvement or mortality benefit [183]. Umifenovir has shown in vitro activity against SARS-CoV-1 [184] and improved radiological findings when added to lopinavir/ritonavir in a small RCT [185], and seems suitable for further development.

\section{Controlling viral diseases and TB: strengths and opportunities Principles of viral containment}

Globalisation, increased urbanisation resulting in large vastly populated and overcrowded cities, and the development of fast mass transit networks and consequent ease of travelling means that a virus can spread across a country or a continent in just a few hours. In the absence of a vaccine or an effective treatment, the tools to control a new viral infection have remained the same as during the 1918 influenza pandemic, i.e. early public health interventions designed to reduce the risk of transmission and spread of infection such as increased respiratory hygiene, cough etiquette and hand washing, voluntary isolation of infected individuals or households as well as quarantine of their contacts, followed by voluntary or mandatory physical distancing measures, restrictions on travel and transportation, and dissemination of basic infection prevention and control messages and advice to the general population [93]. National lockdown is an extreme measure that, while potentially reducing transmission, may also result in the collapse of the economy of a country. These nonpharmaceutical countermeasures aim at reducing the impact of COVID-19 by minimising the number of contacts that result in disease transmission and, thus, reducing the effective reproduction number $\mathrm{R}_{0}$ to below 1 . The reduction of the number of cases during the epidemic peak is crucial to reduce the burden on the healthcare services and other related sectors, and aims to flatten the curve by spreading cases over a longer period of time. This approach, while not necessarily reducing the total number of cases, gains time necessary for the development, production and distribution of effective and safe pharmaceuticals (i.e. vaccines and antiviral drugs), implementation of adequate hospital response and obtaining necessary ICU equipment as well as more sensitive diagnostic tests.

Infection control refers to the different methods and strategies deployed to reduce or prevent the incidence and/or transmission of infections (see the following subsection on "Airborne infection control and workplace safety"). Containment, through early detection, investigation and reporting of cases, together with contact tracing with self-isolation, aims at containing, preventing or delaying the spread of the disease in the community. Geographical containment in a defined area relies on measures to restrict the virus spreading beyond the "containment zone" or "cordon sanitaire", including pharmacological and public health interventions such as intensified surveillance and laboratory testing, movement restrictions in and 
TABLE 2 Drug interactions between tuberculosis (TB) and potential COVID-19 medications

\begin{tabular}{|c|c|c|c|c|c|c|c|c|c|c|c|c|c|c|c|c|c|}
\hline \multirow{2}{*}{\multicolumn{4}{|c|}{$\begin{array}{c}\text { WHO } \\
\text { first-line TB drugs }\end{array}$}} & \multicolumn{14}{|c|}{ WHO second-line TB drugs } \\
\hline & & & & \multicolumn{4}{|c|}{ Group A } & \multicolumn{2}{|c|}{ Group B } & \multicolumn{8}{|c|}{ Group C } \\
\hline INH & RIF & EMB & PZA & LFX & MFX & $\mathrm{BDQ}$ & LZD & CFZ & Cs & DLM & IMI/CIS & MEN & AMI & STR & ETO & PTO & PAS \\
\hline
\end{tabular}

\section{Antivirals}

Atazanavir

Baloxavir marboxil

[239]

Favipiravir

[240, 241]

Galidesivir

Lopinavir/ritonavir

[242, 243]

Oseltamivir

Remdesivir

[242]

Ribavirin

[242]

Umifenovir

[244, 245]

Antibacterials

Azithromycin

[246]

Antiprotozoals

Chloroquine

[247-249]

Nitazoxanide

\begin{tabular}{|c|c|c|c|c|c|c|c|c|c|c|c|c|c|c|c|c|c|}
\hline- & $\downarrow X$ & - & - & $-\varphi$ & $\varphi^{\circ}$ & $4{ }^{\circ}$ & - & $-\bullet$ & - & 4 & - & - & - & - & - & - & - \\
\hline- & $\boldsymbol{\nabla}^{+x^{\#}}$ & - & - & - & - & $\triangle^{+}$ & - & $\Delta^{\S}$ & - & $\triangle^{+}$ & - & - & - & - & - & - & - \\
\hline- & - & - & $-U$ & - & - & - & - & - & - & - & - & - & - & - & - & - & - \\
\hline NA & NA & NA & NA & NA & NA & NA & NA & NA & NA & NA & NA & NA & NA & NA & NA & NA & NA \\
\hline- & $\stackrel{\nabla}{\nabla}$ & - & - & $-\bullet$ & $\frac{1}{+1} 0^{\circ}$ & 40 & - & $-\bullet$ & - & 4 & - & - & - & - & - & - & - \\
\hline- & - & - & - & - & - & - & - & - & - & - & - & - & $\Delta^{f}$ & $\Delta^{f}$ & - & - & - \\
\hline- & $\downarrow x$ & - & - & - & - & - & - & - & - & - & - & - & - & - & - & - & - \\
\hline- & - & - & - & - & - & - & -0 & - & - & - & - & - & - & - & - & - & - \\
\hline- & $\begin{array}{c}\nabla^{\#} \\
\nabla^{-1}\end{array}$ & - & - & - & $\triangle^{n}$ & $\triangle^{+}$ & - & $\triangle^{\S}$ & - & $\triangle^{+}$ & - & - & - & - & - & - & - \\
\hline
\end{tabular}

\begin{tabular}{|c|c|c|c|c|c|c|c|c|c|c|c|c|c|c|c|c|c|}
\hline- & - & - & - & $-\bullet$ & $-\bullet$ & $-\bullet$ & - & $-\bullet$ & - & $-\bullet$ & - & - & - & - & - & - & - \\
\hline
\end{tabular}

\begin{tabular}{|c|c|c|c|c|c|c|c|c|c|c|c|c|c|c|c|c|c|}
\hline- & $\downarrow x$ & - & - & $-\bullet$ & $-\bullet$ & $-\bullet$ & - & $-\bullet$ & - & $-\bullet$ & $-\frac{1}{2}$ & -1 & -3 & -3 & - & - & - \\
\hline- & - & - & - & - & - & - & - & - & - & - & - & - & - & - & - & - & - \\
\hline
\end{tabular}

Continued 


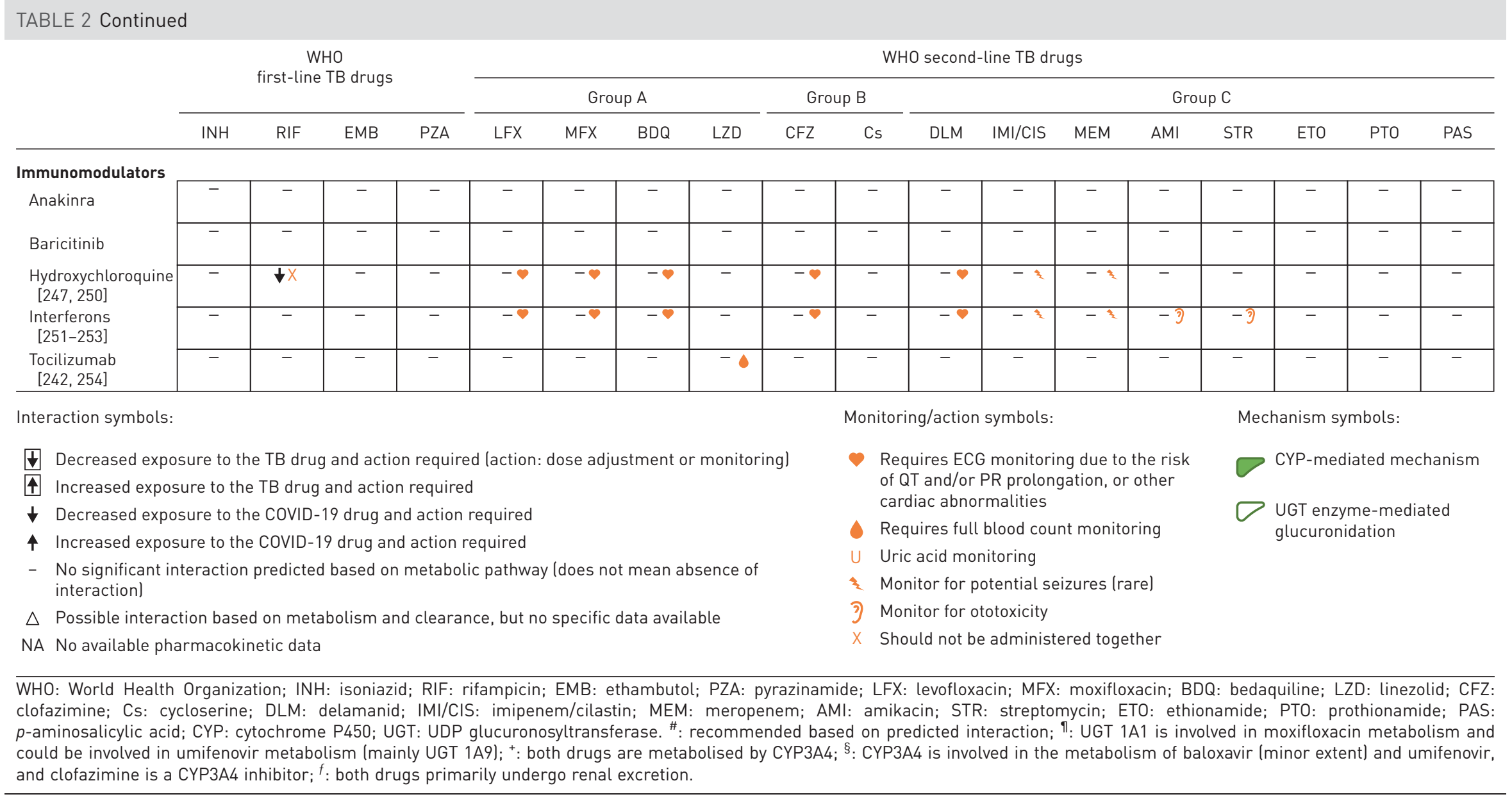


out of the containment zone, and monitoring the area immediately surrounding the containment zone (buffer zone) for secondary infections [186].

Delaying the spread of infection can be achieved by early identification and treatment of cases, monitoring and follow-up of contacts, physical distancing measures such as proscribing public or religious gatherings and closing schools (impacting working parents), sports events or businesses, reducing contact between people. It aims at lowering the epidemic peak, reducing the burden of cases at a given time and maintaining it below healthcare capacity.

A systematic analysis of the responses to the 1918 influenza pandemic showed that in the USA, cities that introduced early social isolation measures experienced a significant reduction of viral spread, approximately 50\% lower peak death rates and nearly $20 \%$ lower cumulative excess mortality than cities that did not, with a consequent reduction on healthcare pressures [187].

\section{Airborne infection control and workplace safety}

Airborne infection control in healthcare settings uses a hierarchy of control measures based on elimination of sources of infection, engineering controls, administrative controls and personal protective equipment (i.e. surgical masks for infectious patients and respirators for healthcare workers and visitors) [188-190]. This approach is described in detail in TB guidelines [188, 189], but can be extended also for viral infections including COVID-19 [191, 192]. As presently under discussion in countries under a post-lockdown phase perspective, the concept is valid also to ensure workplace safety in nonhealthcare settings.

While N95/N99 and FFP2/FFP3 respirators or higher-level respirators including disposable filtering face piece respirators, powered air purifying respirators, elastomeric respirators (defined as per USA and European standards) and eye protection are recommended to protect healthcare staff and other exposed individuals at the workplace level (after adequate training), the use of surgical masks is debated [193, 194]. Although there is agreement on the use of surgical masks to limit the spread of droplet nuclei for isolated symptomatic patients, the potential mass use of surgical masks to limit the community spread of COVID-19 during the early stages of infection and from asymptomatic individuals is strongly discussed [191, 193, 194]. Arguments against their wide use are based on the false sense of protection (e.g. the individual feels the surgical mask protects him/her from acquiring infection) as well as the potential risks of moisture retention, long mask re-use and limited filtration capacity [195]. While the WHO is revising its recommendations, the use of masks among community members has been re-evaluated [194, 196, 197]. Recent ECDC guidance states that face masks used by the general population may reduce the spread of the infection in the community by minimising the excretion of respiratory droplets from infected individuals who have not yet developed symptoms or who remain asymptomatic [198]. In general, all infection control measures are important to prevent infections and render workplaces safe.

The stability of SARS-CoV-2 is similar to SARS-CoV-1, and studies indicate that aerosol and fomite transmission of SARS-CoV-2 is plausible [9], and can be associated with nosocomial spread and superspreading events since it can remain viable and infectious in aerosols for hours and on surfaces up to days [199].

Current evidence provides support for direct contact and respiratory droplets as predominant routes of SARS-CoV-2 transmission [200], and highlights the importance of environmental surface cleaning with a hospital-grade disinfectant and meticulous hand hygiene.

SARS-CoV-2 is inactivated by common disinfection measures such as $5 \mathrm{~min}$ contact with household bleach [201]. The following disinfectants kill the virus: ice-cold acetone (90 s), ice-cold acetone/methanol mixture (40/60, $10 \mathrm{~min}), 70 \%$ ethanol $(10 \mathrm{~min}), 100 \%$ ethanol $(5 \mathrm{~min})$, paraformaldehyde $(2 \mathrm{~min})$ and glutaraldehyde $(2 \mathrm{~min})$. Commonly used brands of hand disinfectants also inactivate SARS-CoV $(30 \mathrm{~s})$ [202]. The ECDC guidance on disinfection of environments in healthcare and nonhealthcare settings potentially contaminated with SARS-CoV-2 recommends products with virucidal activity licensed in the national markets or $0.05 \%$ sodium hypochlorite (dilution $1 / 100$, if household bleach is used, which is usually at an initial concentration of 5\%). For surfaces that can be damaged by sodium hypochlorite, products based on ethanol of at least $70 \%$ can be used [203]. The virus is sensitive to heat $\left(60^{\circ} \mathrm{C}\right.$ for $30 \mathrm{~min}$ ) [202] and UV radiation (60 $\mathrm{min})$ [204].

Outside the host, the virus can survive for 4 days in diarrheal stool samples with an alkaline $\mathrm{pH}$ [202], more than 7 days in respiratory secretions at room temperature, for at least 4 days in undiluted urine, faeces and human serum at room temperature [201], up to 9 days in suspension, $60 \mathrm{~h}$ in soil/water, more than 1 day on hard surfaces such as glass and metal [202], up to $48 \mathrm{~h}$ on plastic surfaces [205], and 6 days in the dried state [202]. 
The virus does not survive well after drying on paper, but lasts longer on disposable gowns compared with cotton gowns [201]. Human coronavirus 229E can remain infectious on high-touch environmental surfaces (polyvinylchloride, laminate, wood and stainless steel) for at least 7 days at ambient temperature $\left(24^{\circ} \mathrm{C}\right)$ and relative humidity conditions (around 50\%) [206].

The specific features of COVID-19, which spreads very rapidly with a short incubation period and infects exponentially thousands of individuals in all age groups [207], calls for the implementation of specific containment measures as discussed in the previous subsection on "Principles of viral containment".

\section{Human resources, equipment and new approaches to clinical management}

The COVID-19 pandemic is, first and foremost, a health crisis [208]. However, it is rapidly also becoming an economic crisis. In a vicious circle, the reduction in economic activities reduces money circulation, tax revenues and finances available for establishing the public health countermeasures needed to control the pandemic. At the same time, social protection measures to ensure a minimum salary to the many workers who cannot be supported by their employers increases the financial constraints at the government level. The poverty generated by the economic crisis is likely to have medium- and long-term consequences, particularly in resource-limited countries, with increases in malnutrition and poverty-related diseases, which include TB.

To mitigate the consequences of this or future pandemics it is important countries develop specific plans with adequate human and financial resources [209]. This will prevent or limit resources currently reserved for other purposes (e.g. for TB programmes) becoming diverted to the emergency [210], including the shortage of PCR reagents being used for COVID-19 diagnosis which may impact on molecular TB diagnosis. Moreover, the emergency plan should be able to ensure rapid procurement and distribution of diagnostics, drugs, ventilators, masks, personal protective equipment and respirators needed to ensure an adequate response and adequate human resources [209, 211]. Telemedicine would be an important approach to deliver care, especially as a means to reduce the risk of cross-contamination caused by close contact [212]. To be effective, as part of an emergency response, telehealth would need to be routinely used in the health system. This would imply a change in the management and the redesign of existing models of care. Moreover, a central system of controlling the pandemic is needed (e.g. in Italy, the Italian Civil Protection Dept [213], which is normally dedicated to seismic hazard or natural disaster assessment and intervention). A central system will ensure prompt coordination of the emergency response and implementation of the emergency plan [211].

\section{Impact of "fear" of viral infections on health services and TB services}

There are many factors affecting access to healthcare: affordability and physical/geographical accessibility are essential; sociodemographic factors (ethnicity, sex, age, marital and socioeconomic status) and psychological factors such as fear can significantly hinder or delay access to TB diagnosis and care.

Fear, defined as an instinctive emotional reaction to a specific, identifiable and immediate threat such as a dangerous animal, infection, deportation or imprisonment, has a protective function associated with defensive behaviours such as hiding or fight-or-flight responses. Fear of TB itself, fear of discrimination (either self-stigma or fear of being stigmatised by others, including healthcare providers) and fear of factors associated with healthcare such as the fear that receiving a diagnosis of TB or TB treatment could affect the way they are perceived by society and even lead to deportation or exclusion are well-recognised barriers to timely access to care [214].

In addition, physical distancing measures imposed to reduce the transmission of COVID-19 (SARS-CoV-2) such as self-quarantine, closure of all nonessential services including small clinics, movement restrictions and limited access to public transport, police patrols, and enforced isolation measures all have a potential deleterious impact on access to TB care. These factors affect all groups, but disproportionately impact those minorities more often afflicted by TB such as migrants, refugee and asylum seekers, ethnic minorities or the poor. The effect on management of nonpandemic conditions including TB, strokes and myocardial infections is not only because of the unwillingness of individuals to attend healthcare facilities for fear of catching infection, but also because anything associated with fever may wrongly be assumed to be caused by the pandemic organism.

\section{Lessons on COVID-19 and TB: lessons learned and common solutions Country response to COVID-19}

The response of European Union (EU)/European Economic Area (EEA) countries and the UK to the COVID-19 epidemic is provided in table 3 [215]. By April 3, 2020, 25 out of 31 (81\%) countries had closed all educational institutions, higher education and secondary schools, primary schools, and day care/nurseries; in some countries primary schools (two out of $31(6 \%)$ ) and/or day care/nurseries (six 
out of $31(19 \%)$ ) remained open. Public spaces were closed in 30 out of 31 (97\%) countries, including closure of museums, theatres, cafes and restaurants, and gyms and sport facilities. Mass gatherings had been cancelled in all 31 countries. In some countries this meant that indoor and outdoor gatherings of more than five persons were forbidden and in others only larger gatherings of more than 1000 persons were banned. Finally, more than half of EU/EEA countries and the UK (18 out of 31 (58\%)) implemented a full national lockdown, i.e. stay-at-home orders for regions or entire countries. Of the 13 countries without national lockdown, one country issued stay-at-home recommendations to the general population and nine countries issued stay-at-home recommendations for risk groups. The assessment of the response shows that there has been a lack of uniformity in the implementation of different measures. An analysis of the efficacy of the different measures at the end of the emergency should guide future policies.

\section{TB and COVID-19 interactions}

There are multiple interactions at the different levels of prevention, diagnosis and treatment between the responses to TB and COVID-19 $[135,136,216]$. Similarities and differences related to infection control and workplace safety have been discussed.

For diagnosis, the possibility of using a platform like Xpert offers synergies, although the risk is that during the COVID-19 emergency the existing equipment will be diverted from TB diagnosis. Personal protective equipment is needed to protect laboratory personnel handling viral specimens $[135,136]$.

Cough is the pivotal symptom to diagnose TB. In the absence of adequate diagnostic tools, the presence of cough, fever and other nonspecific symptoms complicates differential diagnosis of TB, COVID-19 and other respiratory infections [135].

The necessary physical distancing policies are likely to negatively affect active case finding as well as community-based activities which are important to manage TB (and HIV) in high TB burden countries [216]. However, they may reduce transmission of $\mathrm{TB}$, which has already been shown for influenza $[217,218]$. Both clinical and programmatic approaches to TB treatment are also affected in high-burden countries and drug procurement (particularly for second-line drugs) is also likely to suffer.

Last but not least, the expected major economic crisis which will follow the COVID-19 pandemic may result in increased poverty, social disturbances and malnutrition with a profound impact increasing $\mathrm{TB}$ incidence and mortality [219-221].

What we can and cannot learn from TB programmes in response to the COVID-19 pandemic Political commitment, strategic planning, community mobilisation, and research and development are key elements in the battle against either TB or COVID-19. While a sustainable and effective treatment programme is the key to successful control of TB, good pandemic preparation with adequate emergency response capacity is needed when confronted with viruses with pandemic potential such as SARS-CoV-2 or influenza. Early and determined action to contain the COVID-19 epidemic at its localised or importation stage will give more time for reinforcement of care facilities, manpower and supplies [222]. Triage of suspected cases and patients according to their isolation and treatment needs will help to maximise the healthcare throughput with limited resources. Simultaneous measures to contain the spread of the epidemic is necessary to limit the mounting patient load and avoid major breaches in nosocomial infection control and total collapse of the healthcare system.

Breaking the transmission link is the main method for containing an infectious disease in the absence of an effective vaccine. Controlling a respiratory infection at source is often more cost-effective than targeting multiple intervention points downstream for environmental control or personal protection [223]. For TB, wearing a surgical mask can reduce the transmission by $56 \%$ [224]. The evidence for the protective effect of cloth masks is limited and contradictory $[195,225]$. For both diseases, early case detection is important for source control, but case finding may be delayed by inconspicuous or nonspecific symptoms [135]. TB can be stopped at source by effective treatment. Isolation for the whole infectious period is needed to contain the spread of COVID-19. Like TB, contact tracing may only pick up a small portion of COVID-19 cases when widespread local transmission occurs with unclear transmission links [226]. Physical distancing [227] and adjunctive use of face masks for unavoidable person-to-person contact are then the only effective measures to slow the otherwise exponential growth of the COVID-19 epidemic [193]. The current physical distancing and stay-at-home measures imposed due to the COVID-19 pandemic will pose challenges to TB programmes to provide the necessary diagnosis, treatment and care for the people and communities affected by TB. To avoid disruption of TB services, innovative approaches (e.g. virtual care, digital health, community monitoring solutions, etc.) will be necessary [196]. 
TABLE 3 Response measures undertaken in European Union (EU)/European Economic Area (EEA) Member States and the UK at the national level as of April 3, 2020

\begin{tabular}{ccccccc}
\multicolumn{2}{c}{ Closure of educational institutions } & $\begin{array}{c}\text { Closure } \\
\text { of public }\end{array}$ & $\begin{array}{c}\text { Mass } \\
\text { gathering }\end{array}$ & $\begin{array}{c}\text { Stay-at-home } \\
\text { order } \\
\text { lenforced) }\end{array}$ & $\begin{array}{c}\text { Stay-at-home } \\
\text { recommendation } \\
\text { (general population) }\end{array}$ & $\begin{array}{c}\text { Stay-at-home } \\
\text { recommendation } \\
\text { (risk group) }\end{array}$ \\
$\begin{array}{c}\text { and secondary } \\
\text { school }\end{array}$ & school or nursery & spaces & cancellations
\end{tabular}

\begin{tabular}{|c|c|c|c|c|c|c|c|c|}
\hline Austria & $\checkmark$ & $\checkmark$ & $\checkmark$ & $\checkmark$ & $\checkmark$ & $\checkmark$ & $\checkmark$ & \\
\hline Belgium & $\checkmark$ & $\checkmark$ & & $\checkmark$ & $\checkmark$ & $\checkmark$ & & \\
\hline Bulgaria & $\checkmark$ & $\checkmark$ & $\checkmark$ & $\checkmark$ & $\checkmark$ & & & $\checkmark$ \\
\hline Croatia & $\checkmark$ & $\checkmark$ & $\checkmark$ & $\checkmark$ & $\checkmark$ & & & \\
\hline Cyprus & $\checkmark$ & $\checkmark$ & $\checkmark$ & $\checkmark$ & $\checkmark$ & $\checkmark$ & & \\
\hline Czech Republic & $\checkmark$ & $\checkmark$ & $\checkmark$ & $\checkmark$ & $\checkmark$ & $\checkmark$ & & \\
\hline Denmark & $\checkmark$ & $\checkmark$ & $\checkmark$ & $\checkmark$ & $\checkmark$ & & & $\checkmark$ \\
\hline Estonia & $\checkmark$ & $\checkmark$ & & $\checkmark$ & $\checkmark$ & $\checkmark$ & & \\
\hline Finland & $\checkmark$ & $\checkmark$ & & $\checkmark$ & $\checkmark$ & & & $\checkmark$ \\
\hline France & $\checkmark$ & $\checkmark$ & $\checkmark$ & $\checkmark$ & $\checkmark$ & $\checkmark$ & & \\
\hline Germany & $\checkmark$ & $\checkmark$ & $\checkmark$ & $\checkmark$ & $\checkmark$ & & & $\checkmark$ \\
\hline Greece & $\checkmark$ & $\checkmark$ & $\checkmark$ & $\checkmark$ & $\checkmark$ & $\checkmark$ & $\checkmark$ & \\
\hline Hungary & $\checkmark$ & $\checkmark$ & $\checkmark$ & $\checkmark$ & $\checkmark$ & & & \\
\hline Iceland & $\checkmark$ & & & $\checkmark$ & $\checkmark$ & & & $\checkmark$ \\
\hline Ireland & $\checkmark$ & $\checkmark$ & $\checkmark$ & $\checkmark$ & $\checkmark$ & $\checkmark$ & $\checkmark$ & $\checkmark$ \\
\hline Italy & $\checkmark$ & $\checkmark$ & $\checkmark$ & $\checkmark$ & $\checkmark$ & $\checkmark$ & & $\checkmark$ \\
\hline Latvia & $\checkmark$ & $\checkmark$ & & $\checkmark$ & $\checkmark$ & $\checkmark$ & & \\
\hline Liechtenstein & $\checkmark$ & $\checkmark$ & $\checkmark$ & $\checkmark$ & $\checkmark$ & & $\checkmark$ & $\checkmark$ \\
\hline Lithuania & $\checkmark$ & $\checkmark$ & $\checkmark$ & $\checkmark$ & $\checkmark$ & & & \\
\hline Luxembourg & $\checkmark$ & $\checkmark$ & $\checkmark$ & $\checkmark$ & $\checkmark$ & $\checkmark$ & & $\checkmark$ \\
\hline Malta & $\checkmark$ & $\checkmark$ & $\checkmark$ & $\checkmark$ & $\checkmark$ & & & $\checkmark$ \\
\hline Netherlands & $\checkmark$ & $\checkmark$ & $\checkmark$ & $\checkmark$ & $\checkmark$ & $\checkmark$ & & $\checkmark$ \\
\hline Norway & $\checkmark$ & $\checkmark$ & $\checkmark$ & $\checkmark$ & $\checkmark$ & & & $\checkmark$ \\
\hline Poland & $\checkmark$ & $\checkmark$ & $\checkmark$ & $\checkmark$ & $\checkmark$ & $\checkmark$ & & \\
\hline Portugal & $\checkmark$ & $\checkmark$ & $\checkmark$ & $\checkmark$ & $\checkmark$ & $\checkmark$ & & $\checkmark$ \\
\hline Romania & $\checkmark$ & $\checkmark$ & $\checkmark$ & $\checkmark$ & $\checkmark$ & $\checkmark$ & & $\checkmark$ \\
\hline Slovakia & $\checkmark$ & $\checkmark$ & $\checkmark$ & $\checkmark$ & $\checkmark$ & & & \\
\hline Slovenia & $\checkmark$ & $\checkmark$ & $\checkmark$ & $\checkmark$ & $\checkmark$ & $\checkmark$ & & \\
\hline Spain & $\checkmark$ & $\checkmark$ & $\checkmark$ & $\checkmark$ & $\checkmark$ & $\checkmark$ & $\checkmark$ & $\checkmark$ \\
\hline Sweden & $\checkmark$ & & & & $\checkmark$ & & & $\checkmark$ \\
\hline UK & $\checkmark$ & $\checkmark$ & $\checkmark$ & $\checkmark$ & $\checkmark$ & $\checkmark$ & $\checkmark$ & $\checkmark$ \\
\hline
\end{tabular}

The data on response measures are based on information available from official public sources as of Friday April 3, 2020 at 18:00 and may not capture measures being taken by countries that are not reported on publicly available websites. The situation is evolving rapidly and this represents a snapshot of the measures that countries in the EU/EEA and the UK reported to date. The response measures displayed are national measures, reported on official public websites. Response measures collected include: mass gathering cancellations (for specific events or a ban on gatherings of a particular size); closure of public spaces (including restaurants, entertainment venues, nonessential shops, etc.); closure of educational institutions (including day care or nursery, primary schools, and secondary schools and higher education); stay-at-home recommendations for risk groups or vulnerable populations (e.g. the elderly, people with underlying health conditions, physically disabled people, etc.); stay-at-home recommendations for the general population (which are voluntary or not enforced); and stay-at-home orders for the general population (these are enforced and also referred to as "lockdown"). The data on response measures has several limitations. First, there is substantial heterogeneity in physical distancing policies and their implementation between countries. For instance, the level of enforcement of measures may vary between countries and there may be specific rules and exceptions to the measures, making interpretation of the data challenging. The measures displayed in these figures are measures reported at a national level and it should be noted that due to the evolution of the outbreak in certain regions, regional or local measures often preceded national ones. The exact dates of introduction were often available from official sources but delays in their implementation may have occurred. Additionally, availability of public data from official government sources varies among countries. For some countries, data are no longer available on official websites concerning measures that are no longer in force, which may result in the data for more recent measures being more complete.

\section{Consensus statements}

The consensus statements derived from the Delphi process and the level of agreement achieved are summarised in table 4. The ECDC PHE did not participate in the Delphi process and development of table 4.

The scores, from the 37 questionnaires received, exceeded 3 (from intermediate to highest score) in all of the 18 statements, ranging from 3.1 to 4.8 out of a maximum of 5 . The lowest scores were found for the statements on hydroxychloroquine/chloroquine and possible protective effect of BCG (Statements 5 and 12), where less 
TABLE 4 Consensus statements derived from the Delphi process and the level of agreement achieved

1 llowest $2 \quad 3 \quad 4$
4

5 (highest relevancel

Mean \pm sD relevance)

1. Large droplets increase the risk of respiratory viral infection through direct transmission.

2. Respiratory viral infections are more likely to occur in older patients (with or without comorbidities) and infants.

3. Elderly patients are more likely to develop acute respiratory distress syndrome and there is an age-related death risk.

4. Antibodies might neutralise respiratory viruses and, then, decrease the risk of recurrent infections.

5. BCG vaccination might offer protection against COVID-19. RCTs are needed.

6. Severe COVID-19 is associated with rapid virus replication, massive inflammatory cell infiltration in the lung and elevated pro-inflammatory cytokine/chemokine response.

7. High initial SARS-CoV-2 load in the airways, older age ( $\geqslant 65$ years) and comorbidities of the infected individual are associated with worse COVID-19 outcome and thus patients with these risk factors need close attention.

8. The combination of CT scan findings /ground-glass opacity and consolidation), clinical presentation respiratory parameters $\left(\mathrm{S}_{\mathrm{pO}_{2}}\right.$ and $P_{\mathrm{aO}_{2}} / F_{\mathrm{IO}_{2}}$ ) and blood tests (C-reactive proteins, lymphocyte number, fibrinogen, D-dimers, IL-6) helps identifying COVID-19 patients at highest risk for ICU transfer.

9. CD4 T-cell count is key to guide the aetiological evaluation of lung infections in HIV-infected individuals.

10. Temporary immunosuppression induced by TB might increase the susceptibility to influenza viruses.

11. An excess mortality associated with influenza is found among TB patients.

12. Chloroquine and hydroxychloroquine have potential to improve the treatment success rate of COVID-19 patients. RCTs are needed.

13. Public and social distancing reduce the risk of SARS-CoV-2 transmission.

14. Appropriate use of facial masks (surgical masks in the general population; N95 for HCWs performing aerosol-producing activities) on symptomatic patients and their contacts can reduce the risk of SARS-CoV-2 infection by limiting the spread of droplet nuclei from isolated symptomatic patients.

15. SARS-CoV-2 virus remains infectious in the environment on different surfaces for days.

16. Social protection measures and specific national centralised emergency plans can reduce the healthcare and socioeconomic burden of respiratory viral infections resulting in epidemics/ pandemics.

17. Stigma and social discrimination affect all virus-infected population groups but disproportionately the minorities.

18. Late implementation of national lockdown can itself alone be effective in reducing the burden of COVID-19 but it has serious impact on the society and the economy.

$\begin{array}{llllll}0(0.0) & 6(16.2) & 6(16.2) & 10(27.0) & 15(40.5) & 3.9 \pm 1.1 \\ 1(2.7) & 5(13.5) & 10(27.0) & 12(32.4) & 9(24.3) & 3.6 \pm 1.1 \\ 0(0.0) & 0(0.0) & 4(10.8) & 10(27.0) & 23(62.2) & 4.5 \pm 0.7 \\ 0(0.0) & 4(10.8) & 7(18.9) & 17(46.0) & 9(24.3) & 3.8 \pm 0.9 \\ 4(10.8) & 7(18.9) & 10(27.0) & 10(27.0) & 6(16.2) & 3.2 \pm 1.2 \\ 0(0.0) & 0(0.0) & 1(2.7) & 7(18.9) & 29(78.4) & 4.8 \pm 0.5 \\ 0(0.0) & 0(0.0) & 3(8.1) & 7(18.9) & 27(73.0) & 4.7 \pm 0.6 \\ & & & & & \\ 0(0.0) & 1(2.7) & 0(0.0) & 10(27.0) & 26(70.3) & 4.6 \pm 0.6\end{array}$

$\begin{array}{llllll}0(0.0) & 3(8.1) & 7(18.9) & 18(48.7) & 9(24.3) & 3.9 \pm 0.9 \\ 2(5.4) & 6(16.2) & 8(21.6) & 18(32.5) & 9(24.3) & 3.5 \pm 1.2 \\ 1(2.7) & 5(13.5) & 8(21.6) & 15(40.5) & 8(21.6) & 3.7 \pm 1.1 \\ 4(10.8) & 8(21.6) & 10(27.0) & 9(24.3) & 6(16.2) & 3.1 \pm 1.3 \\ 0(0.0) & 0(0.0) & 3(8.1) & 6(16.2) & 28(75.7) & 4.7 \pm 0.6 \\ 0(0.0) & 0(0.0) & 1(2.7) & 9(24.3) & 27(73.0) & 4.7 \pm 0.5\end{array}$

$\begin{array}{llllll}0(0.0) & 5(13.5) & 7(18.9) & 5(13.5) & 20(54.1) & 4.1 \pm 1.1 \\ 0(0.0) & 0(0.0) & 4(10.8) & 14(37.8) & 19(51.4) & 4.4 \pm 0.7\end{array}$

$0(0.0) \quad 5(13.5) \quad 7(18.9) \quad 12(32.4) \quad 13(35.1) \quad 3.9 \pm 1.1$

$3(8.1) \quad 3(8.1) \quad 6(16.2) \quad 8(21.6) \quad 17(46.0) \quad 3.9 \pm 1.3$

Data are presented as $\mathrm{n}(\%)$, unless otherwise stated. BCG: bacille Calmette-Guérin; RCT: randomised controlled trial; SARS-CoV-2: severe acute respiratory syndrome coronavirus $2 ; \mathrm{CT}$ : computed tomography; $S_{\mathrm{pO}_{2}}$ : arterial oxygen saturation measured by pulse oximetry; $P_{\mathrm{aO}}$ : arterial oxygen tension; $F_{\mathrm{IO}_{2}}$ : inspiratory oxygen fraction; IL: interleukin; ICU: intensive care unit; TB: tuberculosis; HCW: healthcare worker.

evidence is available. The highest scores were found for the statements on risk factors, outcomes and transmission (Statements 6 and 7), and for public health and prevention measures (Statements 13 and 14).

The majority of experts scored 4 or 5 (high scores) in all statements except Statements 5 and 12.

The Delphi process suggests the experts tended to agree on the relevance of the statements where more solid and high-quality evidence is available. 


\section{Conclusions}

Altogether in this consensus-based document we describe the effects of epidemic and pandemic viral infections (SARS, MERS, influenza A (H1N1)pdm/09, HIV and COVID-19) and the interactions with TB and the lung; the majority of these diseases are droplet-borne. The diagnostic tools range from nucleic acid detection and molecular techniques to immunoassays and traditional cultures for M. tuberculosis. Core management issues were discussed, including drugs, DDIs, novel therapies, and principles of infection control and workplace safety. COVID-19 and TB interactions were discussed in-depth based on the scant information available so far, which requires broad and in-depth research into the subject. New approaches to clinical management and country responses specifically to COVID-19 were elaborated by the expert panel, as well as opportunities and lessons for future responses.

Acknowledgements: The co-authors from the World Association of Infectious Diseases and Immunological Disorders (WAidid) and Global Tuberculosis Network (GTN) are: Jan-Willem Alffenaar, Emmanuelle Cambau, Rosella Centis, Daniela M. Cirillo, Lia D’Ambrosio, Masoud Dara, Giovanni Delogu, Susanna M.R. Esposito, Jose Figueroa, Delia Goletti, Catherine Wei Min Ong, Giovanni Battista Migliori, Emanuele Pontali, Mario Raviglione, Giovanni Sotgiu, Antonio Spanevello, Simon Tiberi, Martin van den Boom, Dina Visca and Jean-Pierre Zellweger.

Out of 40 experts responding to the invitation, 38 (95\%) endorsed the document as follows. From the Global Tuberculosis Network (GTN): Onno W. Akkerman (The Netherlands), Francois-Xavier Blanc (France), Sergey Borisov (Russian Federation), Anna Cristina Carvalho (Brazil), Muhwa J. Chakaya (Kenya), Margareth Dalcolmo (Brazil), Martin Enwerem (South Africa), Alberto Garcia-Basteiro (Spain), José-María García-García (Spain), Rafael Laniado-Laborín (Mexico), Selene Manga (Peru), Ekaterina Manika (Greece), Alessandro V. Mariani (Brazil), Andrey Maryandyshev (Russian Federation), Alberto Matteelli (Italy), Fernanda Mello (Brazil), Moschos Charalampos (Greece), Luis Adrian Rendon (Mexico), Apostolos Papavasiliou (Greece), Alberto Piubello (Niger), Denise Rossato Silva (Brazil), Isabel Saraiva (Portugal), Barbara Seaworth (USA), Ivan Solovic (Slovakia), Simon Tiberi (UK), Zarir Udwadia (India), Andrey Zagorski (USA) and Richard Zaleskis (Latvia). From the ESCMID Study Group for Mycobacterial Infections (ESGMYC): Ana-Gil Brusola (Spain), Danilo Buonsenso (Italy), Paola Di Carlo (Italy), Francis Drobniewski (UK), Sally Hargreaves (UK), Laura Nellums (UK), Cristina Russo (Italy), Thomas Schön (Sweden), Ulrika Simonsson (Sweden) and Cristina Vilaplana (Spain).

Masoud Dara, Martin van den Boom and A.b.m. Tauhidul Islam from the Word Health Organization read and critically reviewed the manuscript.

Support statement: A. Zumla is a co-Principal Investigator of the Pan-African Network on Emerging and Re-Emerging Infections (PANDORA-IDNET) funded by the European and Developing Countries Clinical Trials Partnership the EU Horizon 2020 Framework Programme for Research and Innovation; and is also in receipt of a National Institutes of Health Research senior investigator award. C.W.M. Ong is funded by Singapore National Medical Research Council (NMRC/TA/0042/2015, CSAINV17nov014); National University Health System, Singapore (NUHS/RO/2017/092/SU/01, CFGFY18P11, NUHS/RO/2020/042/RO5 ${ }^{+}$/ad-hoc/1); National Centre for Infectious Diseases, Singapore (STPRG-FY19-003); and is recipient of the Young Investigator Award, Institut Merieux, Lyon, France. A-G. Märtson was funded by Marie Skłodowska-Curie Actions, grant agreement number 713660-PRONKJEWAIL-H2020-MSCACOFUND-2015. The article is part of the activities of the Global Tuberculosis Network (GTN) and of the WHO Collaborating Centre for Tuberculosis and Lung Diseases, Tradate (ITA-80, 2017-2020-GBM/RC/LDA). Part of the work was supported by the Italian Ministry of Health, Ricerca Corrente (Linea 1 and Linea 4). Funding information for this article has been deposited with the Crossref Funder Registry.

Conflict of interest: None declared.

\section{References}

$1 \quad$ World Health Organization. Global tuberculosis report 2019. Geneva, WHO, 2019.

2 Migliori GB, Tiberi S, Zumla A, et al. MDR/XDR-TB management of patients and contacts: challenges facing the new decade. The 2020 clinical update by the Global Tuberculosis Network. Int J Infect Dis 2020; 92S: S15-S25.

3 Yan J, Grantham M, Pantelic J, et al. Infectious virus in exhaled breath of symptomatic seasonal influenza cases from a college community. Proc Natl Acad Sci USA 2018; 115: 1081-1086.

4 Alonso C, Raynor PC, Goyal S, et al. Assessment of air sampling methods and size distribution of virus-laden aerosols in outbreaks in swine and poultry farms. J Vet Diagn Invest 2017; 29: 298-304.

5 Blachere FM, Lindsley WG, Weber AM, et al. Detection of an avian lineage influenza A(H7N2) virus in air and surface samples at a New York City feline quarantine facility. Influenza Other Respir Viruses 2018; 12: 613-622.

6 Leung NH, Zhou J, Chu DK, et al. Quantification of influenza virus RNA in aerosols in patient rooms. PLoS One 2016; 11: e0148669.

7 Milton DK, Fabian MP, Cowling BJ, et al. Influenza virus aerosols in human exhaled breath: particle size, culturability, and effect of surgical masks. PLoS Pathog 2013; 9: e1003205.

8 Lewis D. Is the coronavirus airborne? Experts can't agree. Nature 2020; 580: 175

9 van Doremalen N, Bushmaker T, Morris DH, et al. Aerosol and surface stability of SARS-CoV-2 as compared with SARS-CoV-1. N Engl J Med 2020; 382: 1564-1567.

10 Arnold FW, Fuqua JL. Viral respiratory infections: a cause of community-acquired pneumonia or a predisposing factor? Curr Opin Pulm Med 2020; 26: 208-214.

11 Jain S. Epidemiology of viral pneumonia. Clin Chest Med 2017; 38: 1-9.

12 Varga Z, Flammer AJ, Steiger P, et al. Endothelial cell infection and endotheliitis in COVID-19. Lancet 2020; 395: 1417-1418. 
13 Jain S, Self WH, Wunderink RG, et al. Community-acquired pneumonia requiring hospitalization among U.S adults. N Engl J Med 2015; 373: 415-427.

14 Jain S, Williams DJ, Arnold SR, et al. Community-acquired pneumonia requiring hospitalization among U.S. children. $N$ Engl J Med 2015; 372: 835-845.

15 Saha S, Chadha M, Al Mamun A, et al. Influenza seasonality and vaccination timing in tropical and subtropical areas of southern and south-eastern Asia. Bull World Health Organ 2014; 92: 318-330.

16 Chadha MS, Potdar VA, Saha S, et al. Dynamics of influenza seasonality at sub-regional levels in India and implications for vaccination timing. PLoS One 2015; 10: e0124122.

17 Madhi SA, De Wals P, Grijalva CG, et al. The burden of childhood pneumonia in the developed world: a review of the literature. Pediatr Infect Dis J 2013; 32: e119-e127.

18 Vareille M, Kieninger E, Edwards MR, et al. The airway epithelium: soldier in the fight against respiratory viruses. Clin Microbiol Rev 2011; 24: 210-229.

19 Ong CW, Elkington PT, Friedland JS. Tuberculosis, pulmonary cavitation, and matrix metalloproteinases. Am J Respir Crit Care Med 2014; 190: 9-18.

20 Jegaskanda S, Reading PC, Kent SJ. Influenza-specific antibody-dependent cellular cytotoxicity: toward a universal influenza vaccine. J Immunol 2014; 193: 469-475.

21 Gupta N, LeGoff J, Chamat $S$, et al. Affinity-purified respiratory syncytial virus antibodies from intravenous immunoglobulin exert potent antibody-dependent cellular cytotoxicity. PLoS One 2013; 8: e69390. Chiu C, Openshaw PJ. Antiviral B cell and T cell immunity in the lungs. Nat Immunol 2015; 16: 18-26. Openshaw PJ, Chiu C. Protective and dysregulated T cell immunity in RSV infection. Curr Opin Virol 2013; 3 : $468-474$.

24 Krishnamoorthy N, Khare A, Oriss TB, et al. Early infection with respiratory syncytial virus impairs regulatory T cell function and increases susceptibility to allergic asthma. Nat Med 2012; 18: 1525-1530.

25 Bystrom J, Al-Adhoubi N, Al-Bogami M, et al. Th17 lymphocytes in respiratory syncytial virus infection. Viruses 2013; 5: 777-791.

Abril-Rodriguez G, Ribas A. SnapShot: immune checkpoint inhibitors. Cancer Cell 2017; 31: 848-848.

Simon AK, Hollander GA, McMichael A. Evolution of the immune system in humans from infancy to old age. Proc Biol Sci 2015; 282: 20143085.

28 Olin A, Henckel E, Chen Y, et al. Stereotypic immune system development in newborn children. Cell 2018; 174: 1277-1292.

29 Chackerian AA, Alt JM, Perera TV, et al. Dissemination of Mycobacterium tuberculosis is influenced by host factors and precedes the initiation of T-cell immunity. Infect Immun 2002; 70: 4501-4509.

30 Wolf AJ, Desvignes L, Linas B, et al. Initiation of the adaptive immune response to Mycobacterium tuberculosis depends on antigen production in the local lymph node, not the lungs. J Exp Med 2008; 205: 105-115.

31 Reiley WW, Calayag MD, Wittmer ST, et al. ESAT-6-specific CD4 T cell responses to aerosol Mycobacterium tuberculosis infection are initiated in the mediastinal lymph nodes. Proc Natl Acad Sci USA 2008; 105: 10961-10966.

32 Kumar A, Farhana A, Guidry L, et al. Redox homeostasis in mycobacteria: the key to tuberculosis control? Expert Rev Mol Med 2011; 13: e39.

33 Ong CWM, Fox K, Ettorre A, et al. Hypoxia increases neutrophil-driven matrix destruction after exposure to Mycobacterium tuberculosis. Sci Rep 2018; 8: 11475.

34 Dwivedi VP, Bhattacharya D, Chatterjee S, et al. Mycobacterium tuberculosis directs T helper 2 cell differentiation by inducing interleukin-lbeta production in dendritic cells. J Biol Chem 2012; 287: 33656-33663.

35 Petruccioli E, Scriba TJ, Petrone L, et al. Correlates of tuberculosis risk: predictive biomarkers for progression to active tuberculosis. Eur Respir J 2016; 48: 1751-1763.

36 Goletti D, Lindestam Arlehamn CS, Scriba TJ, et al. Can we predict tuberculosis cure? What tools are available? Eur Respir J 2018; 52: 1801089.

37 Lin PL, Flynn JL. CD8 T cells and Mycobacterium tuberculosis infection. Semin Immunopathol 2015; 37: 239-249.

38 Chan J, Mehta S, Bharrhan S, et al. The role of B cells and humoral immunity in Mycobacterium tuberculosis infection. Semin Immunol 2014; 26: 588-600.

39 Day CL, Abrahams DA, Lerumo L, et al. Functional capacity of Mycobacterium tuberculosis-specific T cell responses in humans is associated with mycobacterial load. J Immunol 2011; 187: 2222-2232.

40 Day CL, Moshi ND, Abrahams DA, et al. Patients with tuberculosis disease have Mycobacterium tuberculosis-specific CD8 T cells with a pro-apoptotic phenotype and impaired proliferative capacity, which is not restored following treatment. PLoS One 2014; 9: e94949.

41 Chiacchio T, Petruccioli E, Vanini V, et al. Polyfunctional T-cells and effector memory phenotype are associated with active TB in HIV-infected patients. J Infect 2014; 69: 533-545.

42 Rozot V, Vigano S, Mazza-Stalder J, et al. Mycobacterium tuberculosis-specific CD8 ${ }^{+} \mathrm{T}$ cells are functionally and phenotypically different between latent infection and active disease. Eur J Immunol 2013; 43: 1568-1577.

43 Nikolova M, Markova R, Drenska R, et al. Antigen-specific CD4- and CD8-positive signatures in different phases of Mycobacterium tuberculosis infection. Diagn Microbiol Infect Dis 2013; 75: 277-281.

44 Lancioni $\mathrm{C}$, Nyendak M, Kiguli S, et al. $\mathrm{CD} 8^{+} \mathrm{T}$ cells provide an immunologic signature of tuberculosis in young children. Am J Respir Crit Care Med 2012; 185: 206-212.

45 Chiacchio RG, Prioste FE, Vanstreels RE, et al. Health evaluation and survey of zoonotic pathogens in free-ranging capybaras (Hydrochoerus hydrochaeris). J Wildl Dis 2014; 50: 496-504.

46 Joosten SA, van Meijgaarden KE, Del Nonno F, et al. Patients with tuberculosis have a dysfunctional circulating B-cell compartment, which normalizes following successful treatment. PLoS Pathog 2016; 12: e1005687.

$47 \quad$ Li H, Javid B. Antibodies and tuberculosis: finally coming of age? Nat Rev Immunol 2018; 18: 591-596.

48 Jones A, Pitts M, Al Dulayymi JR, et al. New synthetic lipid antigens for rapid serological diagnosis of tuberculosis. PLoS One 2017; 12: e0181414.

49 Biering-Sorensen S, Jensen KJ, Monterio I, et al. Rapid protective effects of early BCG on neonatal mortality among low birth weight boys: observations from randomized trials. J Infect Dis 2018; 217: 759-766.

50 Nemes E, Geldenhuys H, Rozot V, et al. Prevention of $M$. tuberculosis infection with H4:IC31 vaccine or BCG revaccination. N Engl J Med 2018; 379: 138-149. 
Netea MG, Joosten LA, Latz E, et al. Trained immunity: a program of innate immune memory in health and disease. Science 2016; 352: aaf1098.

Moorlag S, Arts RJW, van Crevel R, et al. Non-specific effects of BCG vaccine on viral infections. Clin Microbiol Infect 2019; 25: 1473-1478.

Arts RJW, Moorlag S, Novakovic B, et al. BCG vaccination protects against experimental viral infection in humans through the induction of cytokines associated with trained immunity. Cell Host Microbe 2018; 23: 89-100.

Mukherjee S, Subramaniam R, Chen H, et al. Boosting efferocytosis in alveolar space using BCG vaccine to protect host against influenza pneumonia. PLoS One 2017; 12: e0180143.

Spencer JC, Ganguly R, Waldman RH. Nonspecific protection of mice against influenza virus infection by local or systemic immunization with Bacille Calmette-Guerin. J Infect Dis 1977; 136: 171-175.

World Health Organization. Bacille Calmette-Guérin (BCG) vaccination and COVID-19. Geneva, WHO, 2020.

Miller A, Reandelar MJ, Fasciglione K, et al. Correlation between universal BCG vaccination policy and reduced morbidity and mortality for COVID-19: an epidemiological study. medRxiv 2020; preprint [https://doi.org/10. 1101/2020.03.24.20042937].

Hensel J, McGrail DJ, McAndrews KM, et al. Exercising caution in correlating COVID-19 incidence and mortality rates with BCG vaccination policies due to variable rates of SARS CoV-2 testing. medRxiv 2020; preprint [https:// doi.org/10.1101/2020.04.08.20056051].

Kirov S. Association between BCG policy is significantly confounded by age and is unlikely to alter infection or mortality rates. medRxiv 2020; preprint [https://doi.org/10.1101/2020.04.06.20055616].

Daoud A, Laktineh A, Macrander C, et al. Pulmonary complications of influenza infection: a targeted narrative review. Postgrad Med 2019; 131: 299-308.

Centers for Disease Control and Prevention. Estimated influenza illnesses, medical visits, hospitalizations, and deaths in the United States - 2018-2019 influenza season. 2020. www.cdc.gov/flu/about/burden/2018-2019.html Date last accessed: April 6, 2020.

Rice TW, Rubinson L, Uyeki TM, et al. Critical illness from 2009 pandemic influenza A virus and bacterial coinfection in the United States. Crit Care Med 2012; 40: 1487-1498.

Esposito S, Molteni CG, Daleno C, et al. Impact of pandemic A/H1N1/2009 influenza on children and their families: comparison with seasonal A/H1N1 and A/H3N2 influenza viruses. J Infect 2011; 63: 300-307.

Marchisio P, Baggi E, Bianchini S, et al. Clinical and socioeconomic impact of pediatric seasonal and pandemic influenza. Hum Vaccin Immunother 2012; 8: 17-20.

Metersky ML, Masterton RG, Lode H, et al. Epidemiology, microbiology, and treatment considerations for bacterial pneumonia complicating influenza. Int J Infect Dis 2012; 16: e321-e331.

Song JY, Cheong HJ, Heo JY, et al. Clinical, laboratory and radiologic characteristics of 2009 pandemic influenza A/H1N1 pneumonia: primary influenza pneumonia versus concomitant/secondary bacterial pneumonia. Influenza Other Respir Viruses 2011; 5: e535-e543.

Morens DM, Taubenberger JK, Fauci AS. Predominant role of bacterial pneumonia as a cause of death in pandemic influenza: implications for pandemic influenza preparedness. J Infect Dis 2008; 198: 962-970.

Morens DM, Fauci AS. The 1918 influenza pandemic: insights for the 21st century. J Infect Dis 2007; 195: 1018-1028. Channappanavar R, Perlman S. Pathogenic human coronavirus infections: causes and consequences of cytokine storm and immunopathology. Semin Immunopathol 2017; 39: 529-539.

Peiris JS, Lai ST, Poon LL, et al. Coronavirus as a possible cause of severe acute respiratory syndrome. Lancet 2003; 361: 1319-1325.

Assiri A, Al-Tawfiq JA, Al-Rabeeah AA, et al. Epidemiological, demographic, and clinical characteristics of 47 cases of Middle East respiratory syndrome coronavirus disease from Saudi Arabia: a descriptive study. Lancet Infect Dis 2013; 13: 752-761.

Saad M, Omrani AS, Baig K, et al. Clinical aspects and outcomes of 70 patients with Middle East respiratory syndrome coronavirus infection: a single-center experience in Saudi Arabia. Int J Infect Dis 2014; 29: 301-306. Al-Tawfiq JA, Hinedi K, Ghandour J, et al. Middle East respiratory syndrome coronavirus: a case-control study of hospitalized patients. Clin Infect Dis 2014; 59: 160-165.

Zumla A, Hui DS, Perlman S. Middle East respiratory syndrome. Lancet 2015; 386: 995-1007.

Li W, Moore MJ, Vasilieva N, et al. Angiotensin-converting enzyme 2 is a functional receptor for the SARS coronavirus. Nature 2003; 426: 450-454.

World Health Organization. Emergency preparedness, response: preliminary clinical description of severe acute respiratory syndrome. Geneva, WHO, 2003.

Peiris JS, Chu CM, Cheng VC, et al. Clinical progression and viral load in a community outbreak of coronavirus-associated SARS pneumonia: a prospective study. Lancet 2003; 361: 1767-1772.

Nicholls J, Dong XP, Jiang G, et al. SARS: clinical virology and pathogenesis. Respirology 2003; 8: Suppl., S6-S8. van den Brand JM, Haagmans BL, van Riel D, et al. The pathology and pathogenesis of experimental severe acute respiratory syndrome and influenza in animal models. J Comp Pathol 2014; 151: 83-112.

Raj VS, Mou H, Smits SL, et al. Dipeptidyl peptidase 4 is a functional receptor for the emerging human coronavirus-EMC. Nature 2013; 495: 251-254.

Arabi YM, Arifi AA, Balkhy HH, et al. Clinical course and outcomes of critically ill patients with Middle East respiratory syndrome coronavirus infection. Ann Intern Med 2014; 160: 389-397.

Guan WJ, Ni ZY, Hu Y, et al. Clinical characteristics of coronavirus disease 2019 in China. N Engl J Med 2020; 382: $1708-1720$.

Xu XW, Wu XX, Jiang XG, et al. Clinical findings in a group of patients infected with the 2019 novel coronavirus (SARS-Cov-2) outside of Wuhan, China: retrospective case series. BMJ 2020; 368: m606. Zhou F, Yu T, Du R, et al. Clinical course and risk factors for mortality
Wuhan, China: a retrospective cohort study. Lancet 2020; 395: 1054-1062.

Wu Z, McGoogan JM. Characteristics of and important lessons from the coronavirus disease 2019 (COVID-19) outbreak in China: summary of a report of 72314 cases from the Chinese Center for Disease Control and Prevention. JAMA 2020; 323: 1239-1242.

Alhazzani W, Moller MH, Arabi YM, et al. Surviving Sepsis Campaign: guidelines on the management of critically ill adults with coronavirus disease 2019 (COVID-19). Crit Care Med 2020; 46: 854-887. 
Vitacca M, Nava S, Santus P, et al. Early consensus management for non-ICU ARF SARS-CoV-2 emergency in Italy: from ward to trenches. Eur Respir J 2020; 55: 2000632.

88 Cai J, Xu J, Lin D, et al. A case series of children with 2019 novel coronavirus infection: clinical and epidemiological features. Clin Infect Dis 2020; 71: 1547-1551.

89 Lu X, Zhang L, Du H, et al. SARS-CoV-2 infection in children. N Engl J Med 2020; 382: 1663-1665.

90 Cui Y, Tian M, Huang D, et al. A 55-day-old female infant infected with COVID 19: presenting with pneumonia, liver injury, and heart damage. J Infect Dis 2020; 221: 1775-1781.

91 Liu W, Zhang Q, Chen J, et al. Detection of Covid-19 in children in early January 2020 in Wuhan, China. N Engl J Med 2020; 382: 1370-1371.

92 Shen K, Yang Y, Wang T, et al. Diagnosis, treatment, and prevention of 2019 novel coronavirus infection in children: experts' consensus statement. World J Pediatr 2020; 16: 223-231.

93 European Centre for Disease Prevention and Control. Guidelines for the use of non-pharmaceutical measures to delay and mitigate the impact of 2019-nCoV. Stockholm, ECDC, 2020.

94 Wang Y, Dong C, Hu Y, et al. Temporal changes of CT findings in 90 patients with Covid-19 pneumonia: a longitudinal study. Radiology 2020; 296: E55-E64.

95 Wang W, Xu Y, Gao R, et al. Detection of SARS-CoV-2 in different types of clinical specimens. JAMA 2020; 323 : 1843-1844.

96 Liu Q, Wang RS, Qu GQ, et al. Gross examination report of a COVID-19 death autopsy. Fa Yi Xue Za Zhi 2020; 36: $21-23$.

97 Tian S, Hu W, Niu L, et al. Pulmonary pathology of early-phase 2019 novel coronavirus (COVID-19) pneumonia in two patients with lung cancer. J Thorac Oncol 2020; 15: 700-704.

98 Fox SE, Akmatbekov A, Harbert JL, et al. Pulmonary and cardiac pathology in Covid-19: the first autopsy series from New Orleans. medRxiv 2020; preprint [https://doi.org/10.1101/2020.04.06.20050575].

99 International Severe Acute Respiratory and Emerging Infections Consortium. COVID-19 Report: 27 April 2020. https://media.tghn.org/medialibrary/2020/05/ISARIC_Data_Platform_COVID-19_Report_27APR20.pdf Date last accessed: July 7, 2020.

Rello J, Storti E, Belliato M, et al. Clinical phenotypes of SARS-CoV-2: implications for clinicians and researchers. Eur Respir J 2020; 55: 2001028.

101 Tokman S, Huang L. Evaluation of respiratory disease. Clin Chest Med 2013; 34: 191-204.

102 Azoulay E, de Castro N, Barbier F. Critically ill patients with HIV: 40 years later. Chest 2020; 157: 293-309.

103 Segal LN, Methe BA, Nolan A, et al. HIV-1 and bacterial pneumonia in the era of antiretroviral therapy. Proc Am Thorac Soc 2011; 8: 282-287.

104 Marais BJ, Chakaya J, Swaminathan S, et al. Tackling long-term morbidity and mortality after successful tuberculosis treatment. Lancet Infect Dis 2020; 20: 641-642.

105 Pasipanodya JG, Miller TL, Vecino M, et al. Pulmonary impairment after tuberculosis. Chest 2007; 131: 1817-1824.

106 Walaza S, Tempia S, Dawood H, et al. The impact of influenza and tuberculosis interaction on mortality among individuals aged $\geqslant 15$ years hospitalized with severe respiratory illness in South Africa, 2010-2016. Open Forum Infect Dis 2019; 6: ofz020.

107 Walaza S, Cohen C, Nanoo A, et al. Excess mortality associated with influenza among tuberculosis deaths in South Africa, 1999-2009. PLoS One 2015; 10: e0129173.

108 Mhimbira F, Hiza H, Mbuba E, et al. Prevalence and clinical significance of respiratory viruses and bacteria detected in tuberculosis patients compared to household contact controls in Tanzania: a cohort study. Clin Microbiol Infect 2019; 25: 107.

109 Anonymous. Tuberculosis after influenza. Cal State J Med 1919; 17: 85

110 Ballinger MN, Standiford TJ. Postinfluenza bacterial pneumonia: host defenses gone awry. J Interferon Cytokine Res 2010; 30: 643-652.

111 Park Y, Chin BS, Han SH, et al. Pandemic influenza (H1N1) and Mycobacterium tuberculosis co-infection Tuberc Respir Dis 2014; 76: 84-87.

112 Zurcher K, Zwahlen M, Ballif M, et al. Influenza pandemics and tuberculosis mortality in 1889 and 1918 : analysis of historical data from Switzerland. PLoS One 2016; 11: e0162575.

113 Luo T, Sumi A, Zhou D, et al. Seasonality of reported tuberculosis cases from 2006 to 2010 in Wuhan, China. Epidemiol Infect 2014; 142: 2036-2048.

114 Roth S, Whitehead S, Thamthitiwat S, et al. Concurrent influenza virus infection and tuberculosis in patients hospitalized with respiratory illness in Thailand. Influenza Other Respir Viruses 2013; 7: 244-248.

115 de Paus RA, van Crevel R, van Beek R, et al. The influence of influenza virus infections on the development of tuberculosis. Tuberculosis 2013; 93: 338-342.

116 Yen YF, Pan SW, Su VY, et al. Influenza vaccination and incident tuberculosis among elderly persons, Taiwan. Emerging Infect Dis 2018; 24: 498-505.

117 McShane H. Co-infection with HIV and TB: double trouble. Int J STD AIDS 2005; 16: 95-100.

118 Lawn SD, Harries AD, Williams BG, et al. Antiretroviral therapy and the control of HIV-associated tuberculosis. Will ART do it? Int J Tuberc Lung Dis 2011; 15: 571-581.

119 World Health Organization. WHO consolidated guidelines on tuberculosis: module 1: prevention: tuberculosis preventive treatment. Geneva, WHO, 2020.

120 World Health Organization. WHO operational handbook on tuberculosis: module 1: prevention: tuberculosis preventive treatment. Geneva, WHO, 2020.

121 World Health Organization. WHO policy on collaborative TB/HIV activities: guidelines for national programmes and other stakeholders. Geneva, WHO, 2012.

122 Liu W, Fontanet A, Zhang PH, et al. Pulmonary tuberculosis and SARS, China. Emerging Infect Dis 2006; 12: 707-709.

123 Low JG, Lee CC, Leo YS, et al. Severe acute respiratory syndrome and pulmonary tuberculosis. Clin Infect Dis 2004; 38: e123-e125.

124 Cui W, Fan Y, Wu W, et al. Expression of lymphocytes and lymphocyte subsets in patients with severe acute respiratory syndrome. Clin Infect Dis 2003; 37: 857-859.

125 Goletti D, Lee MR, Wang JY, et al. Update on tuberculosis biomarkers: from correlates of risk, to correlates of active disease and of cure from disease. Respirology 2018; 23: 455-466. 
Lindestam Arlehamn CS, McKinney DM, Carpenter C, et al. A quantitative analysis of complexity of human pathogenspecific CD4 T cell responses in healthy M. tuberculosis infected South Africans. PLoS Pathog 2016; 12: e1005760.

Petruccioli E, Petrone L, Vanini V, et al. IFNgamma/TNFalpha specific-cells and effector memory phenotype associate with active tuberculosis. J Infect 2013; 66: 475-486.

Chiacchio T, Petruccioli E, Vanini V, et al. Impact of antiretroviral and tuberculosis therapies on $\mathrm{CD}_{4}^{+}$and CD8 ${ }^{+}$HIV/M. tuberculosis-specific T-cell in co-infected subjects. Immunol Lett 2018; 198: 33-43.

Petruccioli E, Chiacchio T, Navarra A, et al. Effect of HIV-infection on QuantiFERON-plus accuracy in patients with active tuberculosis and latent infection. J Infect 2020; 80: 536-546.

Wong CY, Wong KY, Law TS, et al. Tuberculosis in a SARS outbreak. J Chin Med Assoc 2004; 67: 579-582.

Ong CWM, Goletti D. Impact of the global COVID-19 outbreak on the management of other communicable diseases. Int J Tuberc Lung Dis 2020; 24: 547-548.

Alfaraj SH, Al-Tawfiq JA, Altuwaijri TA, et al. Middle East respiratory syndrome coronavirus and pulmonary tuberculosis coinfection: implications for infection control. Intervirology 2017; 60: 53-55.

Liu Y, Bi L, Chen Y, et al. Active or latent tuberculosis increases susceptibility to COVID-19 and disease severity. medRxiv 2020; preprint [https://doi.org/10.1101/2020.03.10.20033795].

Maciel ELN, Goncalves EJ, Dalcolmo MMP. Tuberculosis and coronavirus: what do we know? Epidemiol Serv Saude 2020; 29: e2020128.

Tadolini M, Codecasa LR, García-García JM, et al. Active tuberculosis, sequelae and COVID-19 co-infection: first cohort of 49 cases. Eur Respir J 2020; 56: 2001298.

Motta I, Entis I, D’Ambrosio L, et al. Tuberculosis, COVID-19 and migrants: preliminary analysis of deaths occurring in 69 patients from two cohorts. Pulmonology 2020; 26: 233-240.

Ault R, Dwivedi V, Koivisto E, et al. Altered monocyte phenotypes but not impaired peripheral T cell immunity may explain susceptibility of the elderly to develop tuberculosis. Exp Gerontol 2018; 111: 35-44.

Epidemiology Working Group for NCIP Epidemic Response, Chinese Center for Disease Control and Prevention. [The epidemiological characteristics of an outbreak of 2019 novel coronavirus diseases (COVID-19) in China]. Zhonghua Liu Xing Bing Xue Za Zhi 2020; 41: 145-151.

Wang JT, Sheng WH, Fang CT, et al. Clinical manifestations, laboratory findings, and treatment outcomes of SARS patients. Emerging Infect Dis 2004; 10: 818-824.

Reed C, Chaves SS, Perez A, et al. Complications among adults hospitalized with influenza: a comparison of seasonal influenza and the 2009 H1N1 pandemic. Clin Infect Dis 2014; 59: 166-174.

World Health Organization. Systematic screening for active tuberculosis: principles and recommendations. Geneva, WHO, 2013.

amieson DJ, Honein MA, Rasmussen SA, et al. H1N1 2009 influenza virus infection during pregnancy in the USA. Lancet 2009; 374: 451-458.

virus infection. Eur J Clin Microbiol Infect Dis 2012; 31: 547-556.

Mathad JS, Gupta A. Tuberculosis in pregnant and postpartum women: epidemiology, management, and research gaps. Clin Infect Dis 2012; 55: 1532-1549.

Akiyama MJ, Spaulding AC, Rich JD. Flattening the curve for incarcerated populations - Covid-19 in jails and prisons. N Engl J Med 2020; 382: 2075-2077.

Kinner SA, Young JT, Snow K, et al. Prisons and custodial settings are part of a comprehensive response to COVID-19. Lancet Public Health 2020; 5: e188-e189.

Negin J, Abimbola S, Marais BJ. Tuberculosis among older adults - time to take notice. Int J Infect Dis 2015; 32: 135-137.

Pinsky BA, Hayden RT. Cost-effective respiratory virus testing. J Clin Microbiol 2019; 57: e00373-19.

Almekhlafi GA, Albarrak MM, Mandourah Y, et al. Presentation and outcome of Middle East respiratory syndrome in Saudi intensive care unit patients. Crit Care 2016; 20: 123.

Booth CM, Matukas LM, Tomlinson GA, et al. Clinical features and short-term outcomes of 144 patients with SARS in the greater Toronto area. JAMA 2003; 289: 2801-2809.

Midgley CM, Jackson MA, Selvarangan R, et al. Severe respiratory illness associated with enterovirus D68 Missouri and Illinois, 2014. MMWR Morb Mortal Wkly Rep 2014; 63: 798-799.

Zhu N, Zhang D, Wang W, et al. A novel coronavirus from patients with pneumonia in China, 2019. N Engl J Med 2020; 382: 727-733.

Wumkes ML, van der Velden AM, de Bruin E, et al. Microarray profile of the humoral immune response to influenza vaccination in breast cancer patients treated with chemotherapy. Vaccine 2017; 35: 1299-1305.

Goodwin S, McPherson JD, McCombie WR. Coming of age: ten years of next-generation sequencing technologies. Nat Rev Genet 2016; 17: 333-351.

Li CX, Li W, Zhou J, et al. High resolution metagenomic characterization of complex infectomes in paediatric acute respiratory infection. Sci Rep 2020; 10: 3963.

Kufner V, Plate A, Schmutz S, et al. Two years of viral metagenomics in a tertiary diagnostics unit: evaluation of the first 105 cases. Genes 2019; 10: 661.

Gillim-Ross L, Subbarao K. Emerging respiratory viruses: challenges and vaccine strategies. Clin Microbiol Rev 2006; 19: 614-636.

Machado D, Couto I, Viveiros M. Advances in the molecular diagnosis of tuberculosis: from probes to genomes. Infect Genet Evol 2019; 72: 93-112.

Evans D, Sineke T, Schnippel K, et al. Impact of Xpert MTB/RIF and decentralized care on linkage to care and drug-resistant tuberculosis treatment outcomes in Johannesburg, South Africa. BMC Health Serv Res 2018; 18: 973. Goletti D, Sanduzzi A, Delogu G. Performance of the tuberculin skin test and interferon-gamma release assays: an update on the accuracy, cutoff stratification, and new potential immune-based approaches. J Rheumatol Suppl 2014; 91: 24-31.

161 World Health Organization. Clinical management of severe acute respiratory infection when COVID-19 is suspected: interim guidance. Geneva, WHO, 2020.

McCreary EK, Pogue JM. Coronavirus disease 2019 treatment: a review of early and emerging options. Open Forum Infect Dis 2020; 7: ofaa105. 
Hagan G, Nathani N. Clinical review: tuberculosis on the intensive care unit. Crit Care 2013; 17: 240.

Dorward J, Gbinigie K. Lopinavir/ritonavir: a rapid review of effectiveness in COVID-19. 2020. www.cebm.net/ covid-19/lopinavir-ritonavir-a-rapid-review-of-the-evidence-for-effectiveness-in-treating-covid Date last accessed: April 16, 2020.

Cao B, Wang Y, Wen D, et al. A trial of lopinavir-ritonavir in adults hospitalized with severe Covid-19. N Engl J Med 2020; 382: 1787-1799.

Rabie H, Denti P, Lee J, et al. Lopinavir-ritonavir super-boosting in young HIV-infected children on rifampicin-based tuberculosis therapy compared with lopinavir-ritonavir without rifampicin: a pharmacokinetic modelling and clinical study. Lancet HIV 2019; 6: E32-E42.

Lan NT, Thu NT, Barrail-Tran A, et al. Randomised pharmacokinetic trial of rifabutin with lopinavir/ritonavirantiretroviral therapy in patients with HIV-associated tuberculosis in Vietnam. PLoS One 2014; 9: e84866.

Principi N, Esposito S. Chloroquine or hydroxychloroquine for prophylaxis of COVID-19. Lancet Infect Dis 2020; in press [https://doi.org/10.1016/S1473-3099(20)30296-6].

Chen Z, Hu J, Zhang Z, et al. Efficacy of hydroxychloroquine in patients with COVID-19: results of a randomized clinical trial. medRxiv 2020; preprint [https://doi.org/10.1101/2020.03.22.20040758].

Gautret P, Lagier JC, Parola P, et al. Hydroxychloroquine and azithromycin as a treatment of COVID-19: results of an open-label non-randomized clinical trial. Int J Antimicrob Agents 2020; 56: 105949.

Jang $\mathrm{CH}$, Choi JH, Byun MS, et al. Chloroquine inhibits production of TNF-alpha, IL-1beta and IL-6 from lipopolysaccharide-stimulated human monocytes/macrophages by different modes. Rheumatology 2006; 45: 703-710.

Ben-Zvi I, Kivity S, Langevitz P, et al. Hydroxychloroquine: from malaria to autoimmunity. Clin Rev Allergy Immunol 2012; 42: 145-153.

Savarino A, Boelaert JR, Cassone A, et al. Effects of chloroquine on viral infections: an old drug against today's diseases? Lancet Infect Dis 2003; 3: 722-727.

Borba MGS, Val FFA, Sampaio VS, et al. Effect of high vs low doses of chloroquine diphosphate as adjunctive therapy for patients hospitalized with severe acute respiratory syndrome coronavirus 2 (SARS-CoV-2) infection: a randomized clinical trial. JAMA Netw Open 2020; 3: e208857.

5 Food and Drug Administration. FDA cautions against use of hydroxychloroquine or chloroquine for COVID-19 outside of the hospital setting or a clinical trial due to risk of heart rhythm problems. 2020. www.fda.gov/drugs/ drug-safety-and-availability/fda-cautions-against-use-hydroxychloroquine-or-chloroquine-covid-19-outside-hospitalsetting-or Date last accessed: May 4, 2020.

Ducharme J, Farinotti R. Clinical pharmacokinetics and metabolism of chloroquine. Focus on recent advancements. Clin Pharmacokinet 1996; 31: 257-274.

Toniati P, Piva S, Cattalini M, et al. Tocilizumab for the treatment of severe COVID-19 pneumonia with hyperinflammatory syndrome and acute respiratory failure: a single center study of 100 patients in Brescia, Italy. Autoimmun Rev 2020; 19: 102568.

Cantini F, Niccoli L, Matarrese D, et al. Baricitinib therapy in COVID-19: a pilot study on safety and clinical impact. J Infect 2020; 81: 318-356.

Weng $\mathrm{D}, \mathrm{Wu} \mathrm{Q}$, Chen $\mathrm{XQ}$, et al. Azithromycin treats diffuse panbronchiolitis by targeting $\mathrm{T}$ cells via inhibition of mTOR pathway. Biomed Pharmacother 2019; 110: 440-448.

Li H, Zhou Y, Zhang M, et al. Updated approaches against SARS-CoV-2. Antimicrob Agents Chemother 2020; 64: e00483-20.

Li G, De Clercq E. Therapeutic options for the 2019 novel coronavirus (2019-nCoV). Nat Rev Drug Discov 2020; 19: $149-150$.

Wang M, Cao R, Zhang L, et al. Remdesivir and chloroquine effectively inhibit the recently emerged novel coronavirus (2019-nCoV) in vitro. Cell Res 2020; 30: 269-271.

placebo-controlled, multicentre trial. Lancet 2020; 395: P1569-P1578.

Khamitov RA, Loginova S, Shchukina VN, et al. [Antiviral activity of arbidol and its derivatives against the pathogen of severe acute respiratory syndrome in the cell cultures]. Vopr Virusol 2008; 53: 9-13.

Deng L, Li C, Zeng Q, et al. Arbidol combined with LPV/r versus LPV/r alone against Corona Virus Disease 2019: a retrospective cohort study. J Infect 2020; 81: e1-e5.

World Health Organization. WHO interim protocol: rapid operations to contain the initial emergence of pandemic influenza. Geneva, WHO, 2012.

Hatchett RJ, Mecher CE, Lipsitch M. Public health interventions and epidemic intensity during the 1918 influenza pandemic. Proc Natl Acad Sci USA 2007; 104: 7582-7587.

Migliori GB, Nardell E, Yedilbayev A, et al. Reducing tuberculosis transmission: a consensus document from the World Health Organization Regional Office for Europe. Eur Respir J 2019; 53: 1900391.

World Health Organization. WHO guidelines on tuberculosis infection prevention and control: 2019 update. Geneva, WHO, 2019.

Thorne CD, Khozin S, McDiarmid MA. Using the hierarchy of control technologies to improve healthcare facility infection control: lessons from severe acute respiratory syndrome. J Occup Environ Med 2004; 46: 613-622.

Bai Y, Yao L, Wei T, et al. Presumed asymptomatic carrier transmission of COVID-19. JAMA 2020; 323: 1406-1407.

Zou L, Ruan F, Huang M, et al. SARS-CoV-2 viral load in upper respiratory specimens of infected patients. $N$ Engl J Med 2020; 382: 1177-1179.

Leung CC, Lam TH, Cheng KK. Mass masking in the COVID-19 epidemic: people need guidance. Lancet 2020; 395: 945.

Leung CC, Lam TH, Cheng KK. Let us not forget the mask in our attempts to stall the spread of COVID-19. Int $J$ Tuberc Lung Dis 2020; 24: 364-366.

MacIntyre CR, Seale H, Dung TC, et al. A cluster randomised trial of cloth masks compared with medical masks in healthcare workers. BMJ Open 2015; 5: e006577.

Leung CC, Cheng KK, Lam TH, et al. Masking to complement social distancing in saving lives in COVID-19 pandemic. Int J Tuberc Lung Dis 2020; 24: 556-558. 
Esposito S, Principi N, Leung CC, et al. Universal use of face masks for success against COVID-19: evidence and implications for prevention policies. Eur Respir J 2020; 55: 2001260.

European Centre for Disease Prevention and Control. Using face masks in the community: reducing COVID-19 transmission from potentially asymptomatic or pre-symptomatic people through the use of face masks. Stockholm, ECDC, 2020.

Chen YC, Huang LM, Chan CC, et al. SARS in hospital emergency room. Emerging Infect Dis 2004; 10: 782-788. World Health Organization. Modes of transmission of virus causing COVID-19: implications for IPC precaution recommendations. Geneva, WHO, 2020.

Lai MY, Cheng PK, Lim WW. Survival of severe acute respiratory syndrome coronavirus. Clin Infect Dis 2005 41: e67-e71.

Rabenau HF, Cinatl J, Morgenstern B, et al. Stability and inactivation of SARS coronavirus. Med Microbio Immunol 2005; 194: 1-6.

European Centre for Disease Prevention and Control. Disinfection of environments in healthcare and nonhealthcare settings potentially contaminated with SARS-CoV-2. Stockholm, ECDC, 2020.

Duan SM, Zhao XS, Wen RF, et al. Stability of SARS coronavirus in human specimens and environment and its sensitivity to heating and UV irradiation. Biomed Environ Sci 2003; 16: 246-255.

Berger A, Drosten C, Doerr HW, et al. Severe acute respiratory syndrome (SARS) - paradigm of an emerging viral infection. J Clin Virol 2004; 29: 13-22.

Bonny TS, Yezli S, Lednicky JA. Isolation and identification of human coronavirus 229E from frequently touched environmental surfaces of a university classroom that is cleaned daily. Am J Infect Control 2018; 46: 105-107.

Dara M, Sotgiu G, Reichler MR, et al. New diseases and old threats: lessons from tuberculosis for the COVID-19 response. Int J Tuberc Lung Dis 2020; 24: 544-545.

McKee M, Stuckler D. If the world fails to protect the economy, COVID-19 will damage health not just now but also in the future. Nat Med 2020; 26: 640-642.

World Health Organization. COVID-19 strategic preparedness and response plan: operational planning guidelines to support country preparedness and response. Geneva, WHO, 2020.

Qian X, Ren R, Wang Y, et al. Fighting against the common enemy of COVID-19: a practice of building a community with a shared future for mankind. Infect Dis Poverty 2020; 9: 34.

World Health Organization. Critical preparedness, readiness and response actions for COVID-19. Geneva, WHO, 2020.

Smith AC, Thomas E, Snoswell CL, et al. Telehealth for global emergencies: Implications for coronavirus disease 2019 (COVID-19). J Telemed Telecare 2020; 26: 309-313.

Protezione Civile. Coronavirus emergency. 2020. www.protezionecivile.gov.it/home Date last accessed: July 7, 2020. Dubayova T, van Dijk JP, Nagyova I, et al. The impact of the intensity of fear on patient's delay regarding health care seeking behavior: a systematic review. Int J Public Health 2010; 55: 459-468.

European Centre for Disease Prevention and Control. Coronavirus disease 2019 (COVID-19) in the EU/EEA and the UK - eighth update. Stockholm, ECDC, 2020.

World Health Organization. WHO Information note: tuberculosis and COVID-19. Geneva, WHO, 2020.

Soo RJJ, Chiew CJ, Ma S, et al. Decreased influenza incidence under COVID-19 control measures, Singapore. Emerging Infect Dis 2020; 26: 1933-1935.

Taiwan. Emerging Infect Dis 2020; 26: 1928-1930.

Saunders MJ, Evans CA. Fighting poverty to prevent tuberculosis. Lancet Infect Dis 2016; 16: 395-396.

Carter DJ, Glaziou P, Lonnroth K, et al. The impact of social protection and poverty elimination on global tuberculosis incidence: a statistical modelling analysis of Sustainable Development Goal 1. Lancet Glob Health 2018; 6: e514-e522.

Migliori GB, Garcia-Basteiro AL. Predicting the effect of improved socioeconomic health determinants on the tuberculosis epidemic. Lancet Glob Health 2018; 6: e475-e476.

World Health Organization. Report of the WHO-China Joint Mission on Coronavirus Disease 2019 (COVID-19). Geneva, WHO, 2020.

Centers for Disease Control and Prevention. Guidelines for environmental infection control in health-care facilities. 2003. www.cdc.gov/infectioncontrol/guidelines/environmental/index.html Date last accessed: July 7, 2020 Dharmadhikari AS, Mphahlele M, Stoltz A, et al. Surgical face masks worn by patients with multidrug-resistant tuberculosis: impact on infectivity of air on a hospital ward. Am J Respir Crit Care Med 2012; 185: 1104-1109.

European Centre for Disease Prevention and Control. Cloth masks and mask sterilisation as options in case of shortage of surgical masks and respirators. Stockholm, ECDC, 2020.

Li Q, Guan X, Wu P, et al. Early transmission dynamics in Wuhan, China, of novel coronavirus-infected pneumonia. N Engl J Med 2020; 382: 1199-1207. COVID-19 epidemic in Wuhan, China: a modelling study. Lancet Public Health 2020; 5: e261-e270. $84-94$.

Hoffmann M, Kleine-Weber H, Schroeder S, et al. SARS-CoV-2 cell entry depends on ACE2 and TMPRSS2 and is blocked by a clinically proven protease inhibitor. Cell 2020; 181: 271-280.

Richardson P, Griffin I, Tucker C, et al. Baricitinib as potential treatment for 2019-nCoV acute respiratory disease. Lancet 2020; 395: e30-e31.

Morse JS, Lalonde T, Xu S, et al. Learning from the past: possible urgent prevention and treatment options for severe acute respiratory infections caused by 2019-nCoV. Chembiochem 2020; 21: 730-738.

Jordan PC, Stevens SK, Deval J. Nucleosides for the treatment of respiratory RNA virus infections. Antivir Chem Chemother 2018; 26: 2040206618764483.

Furuta Y, Gowen BB, Takahashi K, et al. Favipiravir (T-705), a novel viral RNA polymerase inhibitor. Antiviral Res 2013; 100: 446-454.

Shiraki K, Daikoku T. Favipiravir, an anti-influenza drug against life-threatening RNA virus infections. Pharmacol Ther 2020; 209: 107512. 
Wang RR, Yang QH, Luo RH, et al. Azvudine, a novel nucleoside reverse transcriptase inhibitor showed good drug combination features and better inhibition on drug-resistant strains than lamivudine in vitro. PLoS One 2014; 9: e105617.

236 Abraham GM, Morton JB, Saravolatz LD. Baloxavir: a novel antiviral agent in the treatment of influenza. Clin Infect Dis 2020; in press [https://doi.org/10.1093/cid/ciaa107].

237 Gordon CJ, Tchesnokov EP, Feng JY, et al. The antiviral compound remdesivir potently inhibits RNA-dependent RNA polymerase from Middle East respiratory syndrome coronavirus. J Biol Chem 2020; 295: 4773-4779.

238 Busti AJ, Hall RG, Margolis DM. Atazanavir for the treatment of human immunodeficiency virus infection. Pharmacotherapy 2004; 24: 1732-1747.

239 Shionogi \& Co. Ltd. Review Report: Xofluxa (baloxavir). 2018. www.pmda.go.jp/files/000225380.pdf Date last accessed: April 6, 2020.

240 Madelain V, Nguyen TH, Olivo A, et al. Ebola virus infection: review of the pharmacokinetic and pharmacodynamic properties of drugs considered for testing in human efficacy trials. Clin Pharmacokinet 2016; 55: 907-923.

241 Louthrenoo W, Hongsongkiat S, Kasitanon N, et al. Effect of antituberculous drugs on serum uric acid and urine uric acid excretion. J Clin Rheumatol 2015; 21: 346-348.

242 Liverpool Drug Interaction Group. Interactions with experimental COVID-19 therapies. $2020 . \quad$ www. covid19-druginteractions.org Date last accessed: April 1, 2020.

243 Pandie M, Wiesner L, McIlleron H, et al. Drug-drug interactions between bedaquiline and the antiretrovirals lopinavir/ritonavir and nevirapine in HIV-infected patients with drug-resistant TB. J Antimicrob Chemother 2016; 71: 1037-1040.

244 Deng P, Zhong D, Yu K, et al. Pharmacokinetics, metabolism, and excretion of the antiviral drug arbidol in humans. Antimicrob Agents Chemother 2013; 57: 1743-1755.

245 Song JH, Fang ZZ, Zhu LL, et al. Glucuronidation of the broad-spectrum antiviral drug arbidol by UGT isoforms. J Pharm Pharmacol 2013; 65: 521-527.

246 Lu ZK, Yuan J, Li M, et al. Cardiac risks associated with antibiotics: azithromycin and levofloxacin. Expert Opin Drug Saf 2015; 14: 295-303.

247 Chatre C, Roubille F, Vernhet H, et al. Cardiac complications attributed to chloroquine and hydroxychloroquine: a systematic review of the literature. Drug Saf 2018; 41: 919-931.

248 Krzeminski P, Lesiak A, Narbutt J. Seizures as a rare adverse effect of chloroquine therapy in systemic lupus erythematosus patients: a case report and literature survey. Postepy Dermatol Alergol 2018; 35: 429-430.

249 Bortoli R, Santiago M. Chloroquine ototoxicity. Clin Rheumatol 2007; 26: 1809-1810.

250 Malcangi G, Fraticelli P, Palmieri C, et al. Hydroxychloroquine-induced seizure in a patient with systemic lupus erythematosus. Rheumatol Int 2000; 20: 31-33.

251 Zamorano JL, Lancellotti P, Rodriguez Munoz D, et al. 2016 ESC Position Paper on cancer treatments and cardiovascular toxicity developed under the auspices of the ESC Committee for Practice Guidelines: The Task Force for cancer treatments and cardiovascular toxicity of the European Society of Cardiology (ESC). Eur Heart $J$ 2016; 37: 2768-2801.

252 Shakil AO, Di Bisceglie AM, Hoofnagle JH. Seizures during alpha interferon therapy. J Hepatol 1996; 24 : 48-51.

253 Sharifian MR, Kamandi S, Sima HR, et al. INF-alpha and ototoxicity. Biomed Res Int 2013; 2013 : 295327.

254 Genovese MC, Rubbert-Roth A, Smolen JS, et al. Longterm safety and efficacy of tocilizumab in patients with rheumatoid arthritis: a cumulative analysis of up to 4.6 years of exposure. J Rheumatol 2013; 40: 768-780. 